NIST Technical Note 1932

\title{
A Literature Review of Disaster- Induced Business Interruption and an Exploratory Analysis of the Effects of the 2004 Atlantic Hurricane Season on Florida Establishments at the Zip Code Level
}

David Webb Stanley Gilbert

This publication is available free of charge from: https://doi.org/10.6028/NIST.TN.1932
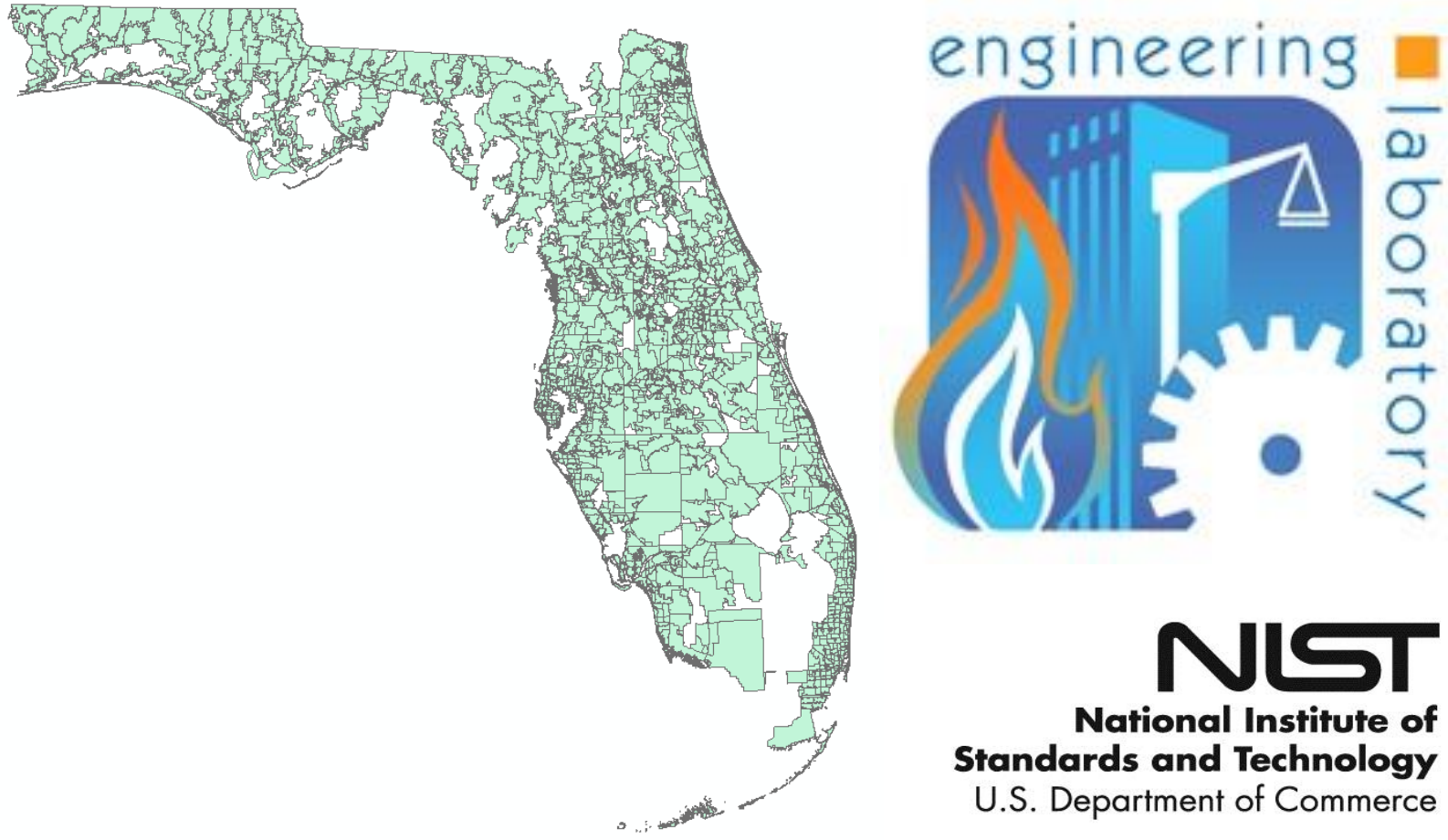

National Institute of Standards and Technology U.S. Department of Commerce 


\title{
A Literature Review of Disaster- Induced Business Interruption and an Exploratory Analysis of the Effects of the 2004 Atlantic Hurricane Season on Florida Establishments at the Zip Code Level
}

\author{
Stanley Gilbert \\ David Webb \\ Applied Economics Office \\ Engineering Laboratory
}

This publication is available free of charge from:

https://doi.org/10.6028/NIST.TN.1932

November 2016

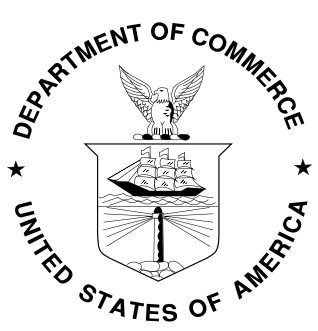

U.S. Department of Commerce

Penny Pritzker, Secretary

National Institute of Standards and Technology 
Certain commercial entities, equipment, or materials may be identified in this document in order to describe an experimental procedure or concept adequately. Such identification is not intended to imply recommendation or endorsement by the National Institute of Standards and Technology, nor is it intended to imply that the entities, materials, or equipment are necessarily the best available for the purpose.

National Institute of Standards and Technology Technical Note 1932 Natl. Inst. Stand. Technol. Tech. Note. 1932, 58 pages (November 2016) CODEN: NTNOEF

This publication is available free of charge from: https://doi.org/10.6028/NIST.TN.1932 


\begin{abstract}
Businesses play a vital role in community resilience. They provide supplies and services in the wake of a major disruption, employment to survivors, and are necessary for a community to begin a full economic recovery. At the same time, businesses themselves are subject to the effects of disasters and disruptive events. They may suffer physical damage to their place of business, lose employees as a result of death and/or loss of homes, and lose customers due to forced closures while repairs are made and/or lifeline infrastructures are brought back to operational status. These impacts generally serve to accelerate any preexisting trends in the region, and can linger for years. Thus understanding the factors that allow a business to survive is vital to establishing a resilient economy.
\end{abstract}

As an exploratory analysis, demographic data from the 2000 Census and 2011 American Community Survey aggregated at the ZIP code level are used in conjunction with damage estimates from the Federal Emergency Management Agency (FEMA) to model the effects of the 2004 Atlantic hurricane season on Florida. Data on the number of business establishments by industry and ZIP code were obtained from the Census County Business Patterns datasets. To prevent the 2007 to 2009 recession from potentially biasing results, a time period from 2000 to 2006 was selected. The analysis also assumes that the 2004 season was a distinct and severe enough event that its impacts are distinguishable from general trends in the data. Analysis was also broken into coastal regions and inland regions to lessen any possible endogeneity. The change in the number of establishments was selected as the dependent variable because establishment level data on closures was unavailable.

A difference in differences (DiD), as well as a graphical analysis on the change in the number of establishments, support the view that the 2004 hurricane season was a significant disruption. However due to the multitude of convoluting factors affecting a state's economy, it is impossible to attribute the full effect to the 2004 hurricane season. Fixed effect regressions using first differences were also run looking at the impact of demographic factors on the change in number of establishments. Regression results were rendered inconsistent by an endogeneity issue; however, the general method here did produce interesting results when incorporating year-specific effects: in many cases, these results agreed with the DiD results and graphical analysis. The regression results imply demographics have a mixed impact, bearing in mind the estimator was inconsistent due to endogeneity. Of more value is that the derived method is general enough that, if a complete data set were present, it could produce meaningful results. 


\section{Acknowledgements}

The authors wish to thank all those who contributed ideas and suggestions for this report. They include Dr. David Butry and Dr. Juan Fung of EL's Applied Economics Office, and Dr. Erica Kuligowski of EL's Fire Research Division, Wildland Urban Interface Fire Group.

\section{Author Information}

David H. Webb

Economist

National Institute of Standards and Technology

Engineering Laboratory

100 Bureau Drive, Mailstop 8603

Gaithersburg, MD 20899-8603

Tel.: 301-975-2644

Email: david.webb@nist.gov

Stanley W. Gilbert

Economist

National Institute of Standards and Technology

Engineering Laboratory

100 Bureau Drive, Mailstop 8603

Gaithersburg, MD 20899-8603

Tel.: 301-975-5261

Email: stanley.gilbert@nist.gov 


\section{Table of Contents}

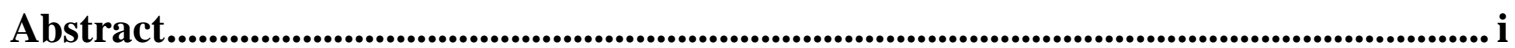

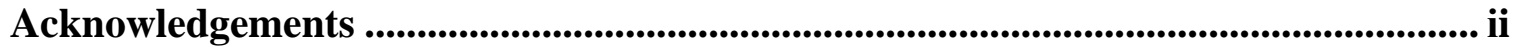

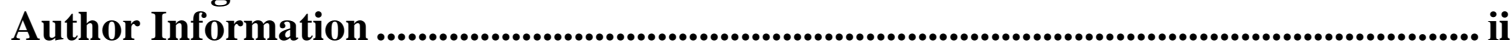

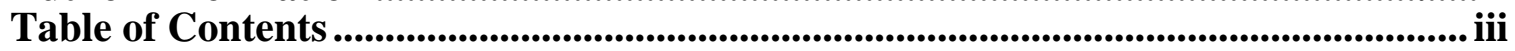

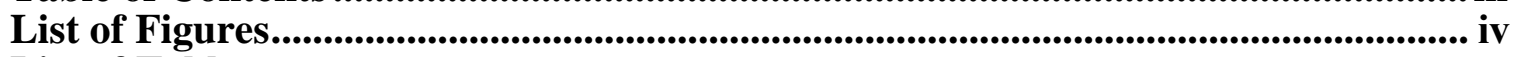

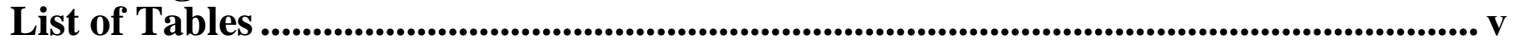

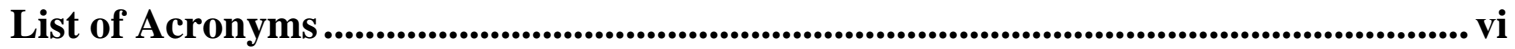

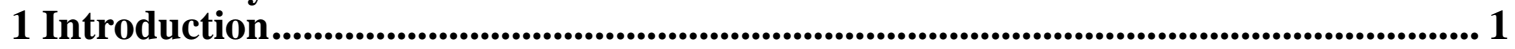

2 Business survival and continuity literature review............................................... 2

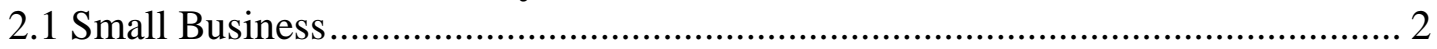

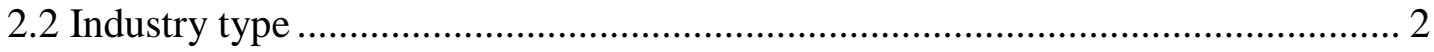

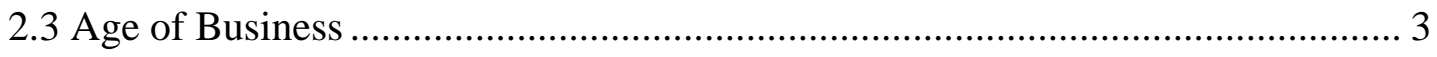

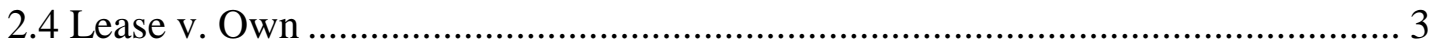

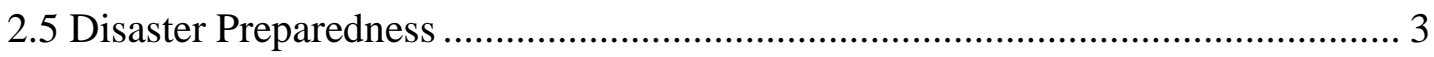

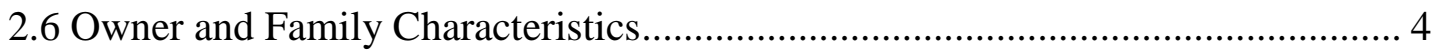

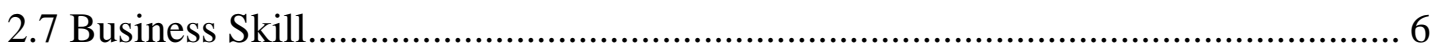

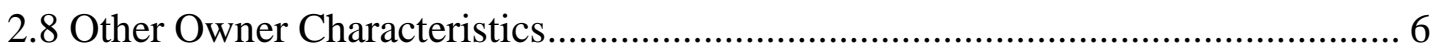

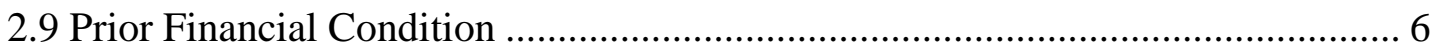

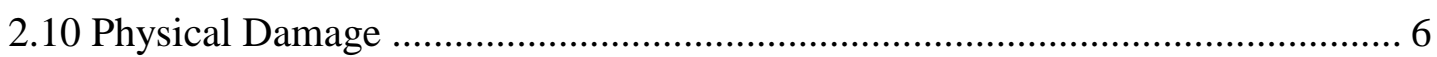

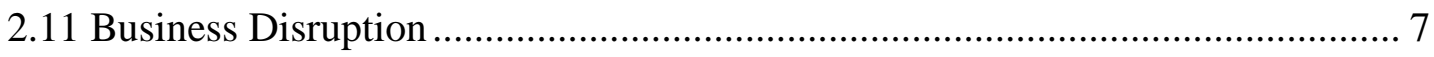

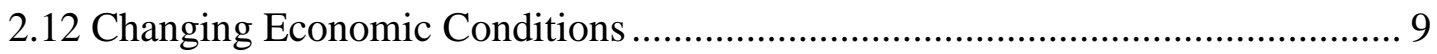

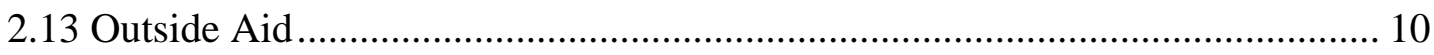

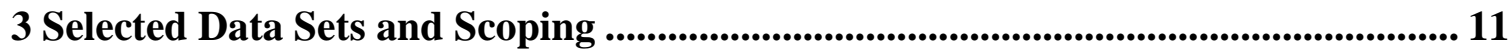

4 Methodology ........................................................................................................................... 15

4.1 Primary Assumption - The "uniqueness" of the 2004 hurricane season............. 15

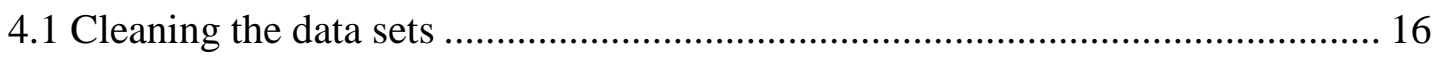

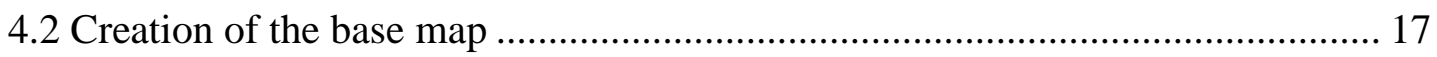

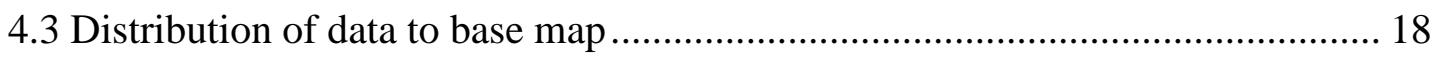

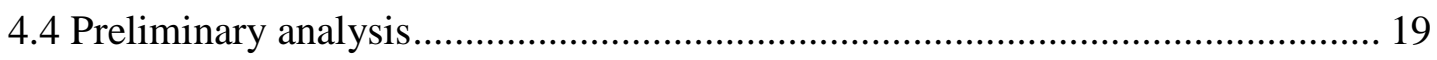

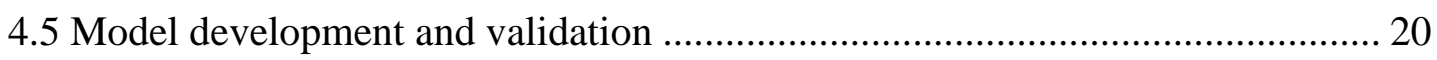

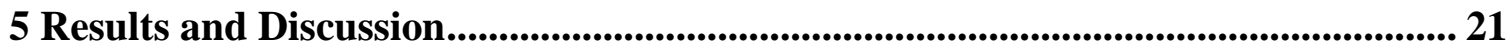

5.1 Industry selection and definition of damaged ZCTA intersections .................... 21

5.2 Mean change in number of establishment results ......................................... 21

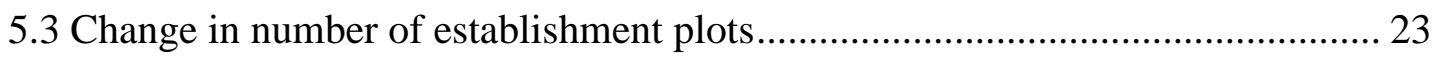

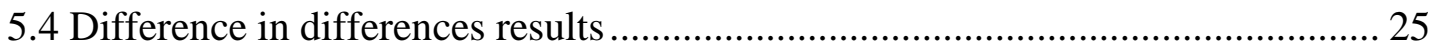

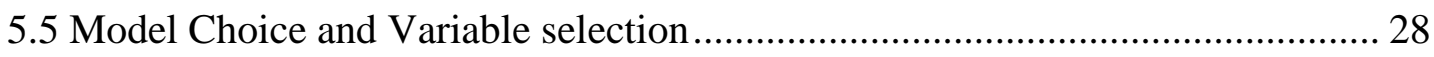

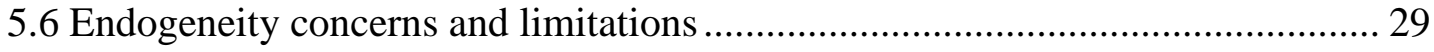

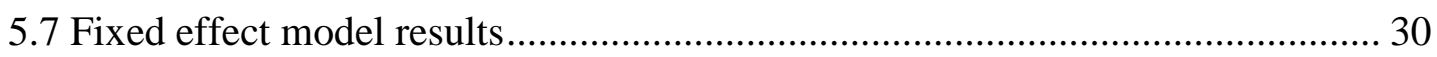

6 Conclusion and Future Work ............................................................................................ 36

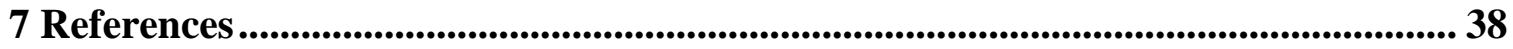

Appendix A. Trend plots of change in the number of establishments over time for industries failing the parallel trends assumption ................................................. 43

Appendix B. Full regression results for individual industries ...................................... 47 


\section{List of Figures}

Figure 1. Map of all ZCTA intersections developed for analysis (3366 ZCTA intersections) .... 18 Figure 2. Plot of change in number of establishments versus time for coastal ZCTA intersections

- all industries $(\Delta$ estAll) 23

Figure 3. Plot of change in number of establishments versus time for inland ZCTA intersections

- all industries ( $\Delta$ estAll) 24 Figure 4. Plot of changing in number of establishments versus time for all ZCTA intersection all industries $(\Delta$ estAll $)$ 25

Figure 5. Plot of change in number of establishments versus time for coastal ZCTA intersections

- manufacturing $(\Delta \mathbf{e s t} 22)$. 43 Figure 6. Plot of change in number of establishments versus time for coastal ZCTA intersections - construction $(\Delta$ est23) 44 Figure 7. Plot of change in number of establishments versus time for inland ZCTA intersections - construction $(\Delta \mathbf{e s t} 23)$ 45 Figure 8. Plot of change in number of establishments versus time for inland ZCTA intersections - real estate $(\Delta$ est53) 46 


\section{List of Tables}

Table 1. Data headings for census and ACS data sets ....................................................... 12

Table 2. Data headings for Census County Business Patterns data ......................................... 14

Table 3. Data headings for FEMA data on owner related registrations................................... 15

Table 4. Mean change in number of establishments in a ZCTA intersection from previous year to listed year (standard deviation is in parenthesis) ................................................................... 22

Table 5. Results of test of parallel trends assumption for selected industries ............................ 26

Table 6. Results of difference in differences analysis for selected industries ........................... 27

Table 7. Regression output for inland ZCTA intersections with all industries included............. 32

Table 8. Regression output for coastal ZCTA intersections with all industries included............ 33

Table 9. Time-dummy regression coefficients for inland regions with experiencing no damage 34

Table 10. Time-dummy regression coefficients for inland regions experiencing damage.......... 35

Table 11. Time-dummy regression coefficients for coastal regions not experiencing damage.... 35

Table 12. Time-dummy regression coefficients for coastal regions experiencing damage.......... 36

Table 13. Regression output for inland ZCTA intersections for the utility sector $(\Delta \mathbf{e s t} 22) \ldots \ldots . .47$

Table 14. Regression output for coastal ZCTA intersections for the utility sector $(\Delta \mathbf{e s t 2 2}) \ldots \ldots . .48$

Table 15. Regression output for inland ZCTA intersections for the construction sector $(\Delta \mathbf{e s t} 23)$

Table 16. Regression output for coastal ZCTA intersections for the construction sector $(\Delta \mathbf{e s t} 23)$

Table 17. Regression output for inland ZCTA intersections for the manufacturing sector

$(\Delta$ est31)

Table 18. Regression output for coastal ZCTA intersections for the manufacturing sector $(\Delta$ est31) 52

Table 19. Regression output for inland ZCTA intersections for the wholesale retail sector $(\Delta \mathrm{est42)}$

Table 20. Regression output for coastal ZCTA intersections for the wholesale retail sector $(\Delta \mathrm{est} 42)$ 54

Table 21. Regression output for inland ZCTA intersections for the retail sector $(\Delta \mathbf{e s t} 4 \mathbf{4}) \ldots \ldots . .55$ Table 22. Regression output for coastal ZCTA intersections for the retail sector $(\Delta \mathbf{e s t 4 4})$....... 56 Table 23. Regression output for inland ZCTA intersections for the real estate sector $(\Delta \mathbf{e s t 5 3}) 57$ Table 24. Regression output for coastal ZCTA intersections for the real estate sector $(\Delta \mathbf{e s t 5 3}) 58$ 


\section{List of Acronyms}

\begin{tabular}{|l|l|}
\hline Acronym & Definition \\
\hline DiD & Difference in differences \\
\hline FEMA & Federal Emergency Management Agency \\
\hline n-significant & Not statistically significant \\
\hline NAICS & North American Industry Classification System \\
\hline s-significant & Statistically significant \\
\hline ZCTA & Zip Code Tabulated Area \\
\hline ZCTA5 & 5-digit Zip Code Tabulated Area \\
\hline ZID & ZCTA Intersection Identifier \\
\hline ZIP & Zone Improvement Plan \\
\hline
\end{tabular}




\section{Introduction}

The damage to a community after a large scale disaster can be debilitating. While individuals and families deal with the personal aspects of disasters and governments and utilities maintain and reestablish their basic functions, business entities are also attempting to recover. Considering the importance of businesses in terms of supporting the local economy and providing goods and services to the community at large their recovery is a vital piece of the overall effort. Businesses, however, are unlike individuals and families struck by disaster, nor are they like public institutions, in a key way. While the recovery of the former is a paramount humanitarian concern and the latter is required to maintain order and provide vital services, most private businesses are primarily driven by economic considerations, with some exceptions such as health care. At the same time businesses, public institutions, and the individuals who make up a community are all intertwined; if one portion suffers it inevitably impacts the others. Understanding how businesses survive or fail in the aftermath of a major adverse event, while a fundamentally different question than individual or governmental recovery, is therefore just as important if a full picture of disaster resilience is sought.

As most major disasters and disruptions are natural (hurricanes, earthquakes, flooding, etc.) they do not "target" individual businesses. Instead their effects tend to be distributed to areas (sections of a community, region of a city or state, etc.), easily affecting entire communities in the case of major events. Severity of the impacts is generally spatially distributed due to underlying geographic features and the nature of the event itself. Impacts on individual businesses and regions can be heterogeneous even when there is no difference in the "strength" of the impact due to socioeconomic, structural, or idiosyncratic factors as well. Understanding business survival requires isolating those factors that are predictive of success or failure and related to business characteristics that can be known prior to disaster and impacts of the event that can be measured post-disaster.

Alesch, Holly et al. (2001) and Headd (2003) noted that business survival and recovery themselves are not necessarily simple concepts to examine and treating recovery as simply a matter of survival of the business is insufficient. A business can survive a disaster but may never return to pre-disaster operations financially or organizationally (Alesch, Holly et al. 2001). In this context a simple ex ante definition of recovery would fail to account for new realities that may emerge after a disaster. Alesch, Holly et al. (2001) instead defined recovery as obtaining a viable state following a major disaster. A similar reasoning is used for the definition of a business failure, including: "a formal declaration of bankruptcy and the business closes," being "placed in receivership for purposes of liquidation of its remaining assets," informal bankruptcy where "the owner closes the doors and walks away forever or when neither the original firm nor the entrepreneur can be found," or the business operates at a level "that systematically and regularly fails to meet fixed plus variable costs" and has "little prospect of continued viability" (Alesch, Holly et al. 2001).

The other issue affecting survivability studies post-disaster is the non-uniform rate of business demise after a disaster (Alesch, Holly et al. 2001, Schrank, Marshall et al. 2013). Furthermore, businesses may reopen shortly after an event, only to struggle and eventually fail years later (Alesch, Holly et al. 2001) while other businesses may appear closed, but are simply recovering at a slower rate than surrounding businesses (Schrank, Marshall et al. 2013). Attempting to separate business failures related to effects of the disaster from those that would have occurred naturally due to the nature of the individual business is also nontrivial (Alesch, Holly et al. 2001). Furthermore, Schrank, Marshall et al. (2013) noted that 
studying communities and businesses after a disaster is typically an entirely post hoc analysis. Research subjects may disperse, the population will change, and it may not be possible to contact owners of demised businesses due to the disruptions caused by disaster related damage.

The focus herein is on the development of a predictive model for the number of establishments at a ZIP code level in Florida before and after the 2004 Atlantic Hurricane season. Specifically, the effects of the four major hurricanes from that season-Charley, Frances, Ivan, and Jeanne-are examined. By developing the model, the goal is to determine whether the 2004 season had a statistical impact on the number of establishments in Florida, as well as determining the direction of influence.

\section{Business survival and continuity literature review}

\subsection{Small Business}

Firm size has been repeatedly shown to be a statistically significant indicator of business survival postdisaster (Tierney 1997, Dahlhamer and Tierney 1998, Alesch, Holly et al. 2001, Basker and Miranda 2012) with evidence that smaller firms are more sensitive in general to economic downturns in the normal business cycle (Fort, Haltiwanger et al. 2013). Alesch, Holly et al. (2001) noted that smaller businesses seemed to be more vulnerable to the effects of disasters due to fewer cash reserves, a heavy reliance on local customers, and not being in a financial position to take mitigation measures like purchasing business interruption insurance and hazard insurance, something further suggested in Zhang, Lindell et al. (2009) and Kroll, Landis et al. (1991). Aldrisch and Auster (1986) noted that larger firms have more resources and better access to financing, as well as greater access to government programs. To that effect, firm size is often considered a proxy for resource access in the literature (Tierney 2007, Fort, Haltiwanger et al. 2013). As noted in Zolin and Kropp (2007), a business operating in the disaster area as part of a national chain may lose the same number of resources as other small businesses, but without severe consequences due to their ability to rely on resources from the chains national operations.

\subsection{Industry type}

Kroll, Landis et al. (1991) found that the economic recovery associated with small business in the wake of the Loma Prieta earthquake varied based on industry type and physical location. Further studies support the impact of industry type on survival, providing evidence that the retail sector is often the most vulnerable industry (Kroll, Landis et al. 1991, Boarnet 1996, Webb, Tierney et al. 2002, Cole, Corbett et al. 2005, Wasileski, Rodríguez et al. 2011) while construction and manufacturing related industries are more resilient (Dahlhamer and Tierney 1998, Corey and Deitch 2011). These results are not necessarily consistent across the literature (Corey and Deitch 2011) but represent the most common findings.

Alesch, Holly et al. (2001) finds further evidence that competition within the specific industry and how crucial the product is to the community are factors as well. This is true of retail and wholesale industries where fierce competition is typical. The closure of a business for a few days in the retail sector means any open competitors gain a distinct advantage. As for product necessity, in the wake of a disaster supplies to rebuild, food, and medication are all purchases which cannot be put off without severe consequences. Other products, such as clothes, are not immediate necessities but eventually require consideration while products with a limited market niche or those that are unnecessary can be deferred 
indefinitely. As such, businesses that provide vital supplies and services have an advantage post disaster (Alesch, Holly et al. 2001).

\subsection{Age of Business}

The age of the business was found to be a poor predictor of business failure in the immediate aftermath of Katrina, however it proved to be a better predictor of business survival over a longer time frame (Marshall, Niehm et al. 2015). This fits into the general concept of the "liability of newness" which Dahlhamer and Tierney (1996) found to hold in the aftermath of the Northridge earthquake. Such a result is not surprising, given that newer firms tend to be more sensitive to changes in the economy in general (Fort, Haltiwanger et al. 2013).

\subsection{Lease v. Own}

The form of building ownership with regards to lease or own, with home-run businesses as a special subset, had no significant ${ }^{1}$ impact according to the literature. Asgary, Anjum et al. (2012), Dahlhamer and Tierney (1996), Webb, Tierney et al. (2002) and Wasileski, Rodríguez et al. (2011) found no significant relationship between recovery and the form of ownership. Home-based businesses are potentially different than other forms of ownership (Marshall, Niehm et al. 2015). Home-based businesses and non-residential structures are not necessarily built to the same building codes, and the owners of home-based businesses may have more incentive to ensure their structure is capable of surviving disaster. Furthermore, Dahlhamer and D'Souza (1995) indicates that homeowners tend to prepare more for disaster than renters. Whether or not this is due to a greater vested interest or simply that renters do not have as much freedom or motivation to alter their property is not discussed. Headd (2003) found that being home-based is a lower cost option than a separate address for the business, which increases survivability. A preference for the home-based lifestyle may also play a role, allowing home-based business owners to keep a struggling business in operation longer, making them less likely to fail (Headd 2003).

\subsection{Disaster Preparedness}

Multiple studies find that preparation for disaster is not a significant factor in predicting business survival (Cavanaugh 2000, Webb, Tierney et al. 2002, Marshall, Niehm et al. 2015). The authors offered some theories for why this might be, such as focusing on employee life-safety and not incorporating business continuity considerations, not employing a sufficient amount of preparation, or not preparing for off-site disaster effects such as infrastructure ${ }^{2}$ disruptions (Webb, Tierney et al. 2000). The level of preparedness appears to primarily be a factor of the size of the business, as larger businesses tend to have staff dedicated to preparedness and more access to financial resources to fund preparedness initiatives (Kroll, Landis et al. 1991, Dahlhamer and Tierney 1998, Webb, Tierney et al. 2000, Tierney 2007). Other factors have been identified as influencing the level of preparedness, such as the legal form

\footnotetext{
${ }^{1}$ Significant in the context of the literature review means statistically significant as defined by the authors of the referenced paper. In all cases in this text the referenced source used a level of significance of $10 \%$ or better for the specified result

2 The literature tends to use "lifeline" when referring to important infrastructure elements. In keeping with the "Community Resilience" efforts of the National Institute of Standards and Technology the term "Infrastructure" is used in lieu of "lifeline" where appropriate
} 
of ownership (Barman, Majumder et al. 2012), but on an inconsistent basis (Webb, Tierney et al. 2000). Asgary, Anjum et al. (2012) did find, however, that knowing recovery priorities in the wake of a disaster was a significant factor in recovery time after the 2010 Pakistan floods. Location is also presented as a significant factor in Marshall, Niehm et al. (2015), which is not surprising, given disasters often have some distribution of strength geographically. At the same time, it is not always easy to predict which physical addresses are more susceptible to damage prior to disaster, consider the track of a hurricane or the location of the epicenter of an earthquake, making location difficult to use as a predictor predisaster.

\subsection{Owner and Family Characteristics}

Owner characteristics such as gender, race, and the role of family have been shown to have some impact on resilience and business survival after a disaster. Danes, Lee et al. (2009) attributes this difference to findings in the literature of females being generally more risk averse regarding financial risk than males, making them more accepting of financial aid. Female owners also were found to rely on temporary help in high demand times while male owners relied more on crossover of family and firm. Crossover is similar to temporary aid except family may be willing to work for less pay, while temporary help is generally priced by labor demand. Both strategies resulted in weakened firm resilience (Danes, Lee et al. 2009).

In examining firm performance during the Great Recession, Jarmin, Krizan et al. (2014) found female, non-Caucasian owned firms, excluding Asian owned firms, tended to lag behind male, Caucasian owned firms in terms of employment growth and survival. This finding is corroborated by Marshall, Niehm et al. (2015) which focused on businesses affected by Hurricane Katrina. Female owned businesses were also more likely to reopen before closing at a later date than male owned businesses; however, in this group ethnicity was not found to be a significant factor. In comparing closures related to Hurricane Andrew and the Loma Prieta earthquake, no statistically significant relationship was found between survival and race or gender (Wasileski, Rodríguez et al. 2011), nor was gender found to be significant in the wake of the 2010 Pakistan floods ${ }^{3}$ (Asgary, Anjum et al. 2012). Webb, Tierney et al. (2002) also found gender to be a non-factor in recovery.

While the reasoning for the disparate findings on gender in the wake of disasters does not exist in the literature, what is worth noting is that much of the literature indicates that female-owned businesses tend to be less successful than male-owned businesses in general (Rosa, Carter et al. 1996, Boden and Nucci 2000, Fairlie and Robb 2009). A consistent theme is that women tended to have lower levels of startup capital as well as less managerial experience resulting in relatively less human capital than their male counterparts (Boden and Nucci 2000, Fairlie and Robb 2009). Fairlie and Robb (2009) present a few other possible reasons for the differences in the performance of female-owned businesses, finding that women tend to be overrepresented in the retail and service industries while being underrepresented in construction. The fact that women were found to work fewer hours and had potentially different motivations were discussed in Fairlie and Robb (2009), though the reasoning for these observations was not given. Limitations in the data and the author's assumptions precluded the use of hours worked and motivation in the regression model used in Fairlie and Robb (2009). Female-owned firms were found to be $12.9 \%$ more likely to close, $52.6 \%$ less likely to have profits exceeding $\$ 10000$ and had annual mean

\footnotetext{
${ }^{3}$ Race was not considered in the analysis
} 
sales around $80 \%$ less than the mean sales of male-owned businesses (Fairlie and Robb 2009). Thus, if there is an effect, then it may be that the effect of gender after disaster is an exacerbation of existing trends in business survival and success.

Contrary findings indicating that gender is not a significant factor in business success and survival are found in Kalleberg and Leicht (1991). In Kalleberg and Leicht (1991) the authors acknowledged some potential issues with their work, such as the use of subjective measures of success, and the examined time period may have been insufficiently long to cover variations in the business cycle. The authors found that a lack of experience was not significant in determining business success, which was defined as a growth in earnings from one year to the next. In terms of their definition, there was no difference in success between male and female owned businesses, though the mean earnings of female owned businesses were found to be $\$ 8000$ less on average. Another study found that, in terms of sole male and sole female owned businesses in the UK, there was no difference in performance (Elizabeth and Baines 1998). The same study found however, that cultural presuppositions on gender roles were more likely to be seen in spouse-owned businesses, and that these businesses tended to underperform relative to sole-owned firms.

While the role of gender on business survival is researched to some extent in the literature, the underlying reasons for these differences are not as thoroughly examined. One possible reason may be found in the work of Dash, Morrow et al. (2007), which suggests that traditional views of gender roles play a part. They suggest that in the wake of disaster there is a tendency to revert to traditional gender roles, even if they were not prevalent pre-disaster. Another possibility is that many female-dominated industries are more vulnerable post-disaster. For instance, in the aftermath of Katrina women saw a decrease in labor force participation and average wages, the opposite effect that was seen for men (Enarson 2010). The primary reason for this was that female-dominated industries, like service work in childcare, health, and education, declined at a higher rate (Jones-DeWeever 2007). It may be that women are vulnerable to negative events due in some part to being represented more in vulnerable industries.

The owner's familial circumstances also have been investigated as a potential factor in recovery. Asgary, Anjum et al. (2012) found that in the wake of the 2010 Pakistan floods almost $18.6 \%$ of businesses relied on familial support in the disaster's aftermath. This figure was much higher than the $6.6 \%$ that relied on government support while being utilized less than personal savings ( $37.2 \%)$, nongovernmental organizations (24.9\%), and borrowing money (22.8\%). The financial support of family and friends was found to also be a statistically significant variable, predicting a faster recovery time (Asgary, Anjum et al. 2012).

Other sources have found that family can have a negative effect. As noted in Alesch, Holly et al. (2001), a disaster is often an all-encompassing event, affecting the totality of a person's life. In the wake of a disaster business owners may be forced to deal simultaneously with family issues, such as loss or injury, and business related issues (Tierney 2007). This can inhibit the recovery of the business side as the human costs of tragedy can be difficult, if not impossible, to fully contend with. Such costs are revealed through some of the anecdotes presented in Alesch, Holly et al. (2001), which describe the complications specific business owners faced in the aftermath of disaster. Marshall, Niehm et al. (2015) further found that the size of the household was a significant positive predictor of closure in the 
immediate aftermath of Katrina, but a significant negative predictor of a business reopening, only to close by 2013.

\subsection{Business Skill}

The skill of the business owner can also play a role in survival. Several terms appear in the literature, and none are necessarily identical in meaning, including "adaptability," "entrepreneurial skill," and "owner resilience." However, the aforementioned terms all generally relate to the ability of an owner to persevere in the wake of disaster whether it is through business acumen or force of will. Marshall, Niehm et al. (2015) for instance, found that owner resilience, measured using a scale developed by Vaishnavi, Connor et al. (2007), was not a significant predictor of business demise immediately after Katrina, but was a significant negative predictor of business closure a year after the disaster, provided the business had reopened prior. Alesch, Holly et al. (2001) used a 3-point scale for "Entrepreneurial Skill" with -1 corresponding to businesses owners who assumed the economic climate would simply return to its pre-disaster state, 0 for those who put some thought into recovery but did little, and 1 for those owners who responded proactively to the changes in the business environment and attempted to adapt. In doing so, the "Entrepreneurial Skill" variable was found to be significant in predicting survival.

\subsection{Other Owner Characteristics}

A host of other variables appear throughout the literature with regards to owner characteristics. Experience with previous disasters or closures has been shown to be a significant benefit to survival while education level has routinely been found insignificant (Asgary, Anjum et al. 2012, Marshall, Niehm et al. 2015).

\subsection{Prior Financial Condition}

The prior financial condition of the business has been found to be a significant factor in predicting business survival immediately after a disaster (Dahlhamer and Tierney 1998, Marshall, Niehm et al. 2015). Alesch, Holly et al. (2001) took a similar tack, using the position of the business on the industry curve as well as its stability prior to the disaster to determine its financial condition. The authors found that having good pre-disaster health translated into good post-disaster health. Tierney and Webb (2001) noted however that pre-disaster financial condition was not necessarily a good indicator of long-term recovery, with the authors suggesting that changing post-disaster trends eventually have more influence on recovery or that lingering issues caused by a natural disaster slowly erode any benefits of predisaster financial strength.

\subsection{Physical Damage}

Physical damage to an establishment or its contents is an important consideration after a disaster. A somewhat surprising finding in the literature that the physical damage to a business or its contents is not necessarily a strong predictor of business survival on the aggregate (Alesch, Holly et al. 2001, Chang and Falit-Baiamonte 2002). Chang and Falit-Baiamonte (2002) further finds evidence that physical damage may not even be a significant predictor of business losses. One potential explanation for this is that most businesses have appropriate insurance coverage, mitigating the financial losses due to a disaster - although Tierney (1995), examining the Des Moines floods, found many small businesses lacked sufficient coverage and may simply have absorbed any direct losses. Alesch, Holly et al. (2001) 
noted that insurance, while not a guarantee of survival, protects equity and allow more options after clean up. Along those lines they found a significant positive correlation between asset loss without insurance and business demise (Alesch, Holly et al. 2001). Tierney (2007) noted that, while damage was an important consideration, many of the challenges facing buildings post-disaster are independent of the amount of physical damage to the structure. If damage is insignificant in terms of predicating business demise, then it may be the case that other effects of the disaster are more pertinent, and not necessarily that direct physical damage plays no part.

There is literature that counters the view that physical damage is not significant. Damage to the establishment structure was had a significant impact in the wake of the 2010 Pakistan floods, however it is unknown whether differences between the United States and Pakistani insurance markets, culture, and general business climate played a role in overall recovery (Asgary, Anjum et al. 2012). Wasileski, Rodríguez et al. (2011) found that damage was a predictor of establishment closure provided the damage was disruptive to operation. They relied on a surveys of business owners in the wake of the Loma Prieta earthquake and Hurricane Andrew, and found a majority of businesses felt the damage to their business was disruptive in both cases. The discrepancy in the literature could be due to a number of reasons, ranging from the specific nature of the disaster or impacted region to differences in the methodology, or the data and definition issues previously mentioned when attempting to study business demise.

\subsection{Business Disruption}

More pertinent, based on literature, post-disaster factors include the amount of disruption the business endures and changing economic conditions in the wake of a disaster (Webb, Tierney et al. 2000). The former occurs for multiple reasons; the cleanup required immediately after a disaster, damage to the physical structure of the business requiring repair or relocation, loss of inventory, or the cutting off of services such as transportation, electricity, or water. Other disruptions include the difficulty sending and receiving shipping, and disruptions to employee or customer access to the business itself. In cases of extensive damage or a region being cutoff, disruptions in business may require temporary or permanent relocation of the physical address, adding more delays and financial costs. Complicating matters is the fact that a business does not need to be directly damaged by a disaster to experience disruption, meaning localized damage can have a widespread effect on businesses if the damaged area provides infrastructure access (Zhang, Lindell et al. 2009) and many businesses are not aware of how much they depend on regional infrastructure (Tierney 2007).

Webb, Tierney et al. (2002), in comparing the effects of the Loma Prieta earthquake and Hurricane Andrew, found that the length of business closure and amount of disruptive damage were significant indicators of business demise, especially the duration of closure of the business. A separate study on the same two disasters found some form of infrastructure interruption as a significant factor in business closure (Wasileski, Rodríguez et al. 2011). For the Loma Prieta earthquake, disruption to phone and electric systems, as well as disruptive damage to the physical structure, were all significant predictors of business closure. For Andrew a coupling of the business environment and transportation disruptions was one of the significant factors (Wasileski, Rodríguez et al. 2011). The negative impact of business interruptions on survivability is further supported by Dahlhamer and Tierney (1998), Tierney (1995) and Tierney (1997). It should be noted that not all forms of disruption have been found to be consistently significant, indicating the specific nature of the disaster and resulting damage may drive which factors 
are the most impactful; e.g. Wasileski, Rodríguez et al. (2011) found transportation problems to be statistically insignificant, while others noted significance (Chang 2000).

A study of the aftermath of the 2010 floods in Pakistan in Asgary, Anjum et al. (2012) revealed that the majority of businesses affected by the flood saw interruptions in their business operations of one to three months with many lasting up to five months. Of those businesses studied, $90 \%$ reopened within 6 months, although at the time of the study $75 \%$ were operating at a loss (Asgary, Anjum et al. 2012). Significant factors in the length of the recovery time were dependent on water and transportation service, damage to inventory, and disruption to the supply chain. Oddly, while dependence on transportation was a significant factor, damage to roads and bridges was not.

To estimate how important they are to business continuity, Nigg (1995) evaluated the dependence of businesses on infrastructure in Memphis, Tennessee. In a random survey, businesses in Memphis ranked the importance of each service (Electricity, Water, Natural Gas, Wastewater Treatment, and Telephone) in terms of operating at normal conditions. Electricity and telephone services were found to "Very Important," the highest classification, for $82 \%$ and $78 \%$ of businesses respectively. The remaining services had a more uniform response among the four levels. Nigg (1995) also found that the loss of even one service could cause businesses to close immediately, with electricity and telephone and telecommunication services being the most crucial. Furthermore, $98 \%$ of businesses expected to experience modest (33\%), major (37\%), or extreme (27\%) disruptions in the event of the loss of two to four services (Nigg 1995). Not only can infrastructure interruptions cause businesses to close, they occur in the larger context of the disaster effected region. Thus customers may not be able to reach open businesses due to transportations disruptions, or their own issues with infrastructure disruptions.

The September 11 attacks on the World Trade Center offer some insight on how lasting infrastructure disruptions can be. Mendonça, Lee et al. (2004) found that infrastructure disruptions continued for months after the initial event. While not directly comparable to a natural disaster, the infrastructure disruptions from the September $11^{\text {th }}$ attacks reveal how even an event localized in a geographically small area can create lingering disruptions to key services. Chang (1998) developed an exponential restoration model later used by Shinozuka, Rose et al. (1998) and Reed, Powell et al. (2010) to estimate expected restoration times with the former finding that the restoration of electricity typically took under two weeks except for the most damaged regions, while the latter estimated about 22 days for the restoration of $99.8 \%$ of electrical services.

A disaster-oriented look at how the loss of transportation can affect businesses was undertaken in Gordon, Richardson et al. (1998) where the authors estimated the relevant business interruptions due to the Northridge earthquake. Local business interruption impacts totaled at least $\$ 1.5$ billion. The losses were a result of an estimated 15725 person-years lost due to transportation disruptions. In total, the average commuter (out of 248 respondents) missed 11 days of work while the average business (number of respondents not stated in paper) lost 14 full days. Further research by Boarnet (1996), also examining the Northridge earthquake, and Chang (2000), examining the economic impacts on transportation after the Kobe 1994 earthquake, supports the claim that transportation disruptions have a significant impact and can last long term. One area vital to small business affected by transportation problems is the loss of access to the physical business for customers and employees. Respondents in a survey study of the Northridge earthquake ranked it as one of their largest problems resulting in real financial losses (Kroll, Landis et al. 1991). 


\subsection{Changing Economic Conditions}

One of the major issues that arises after a disaster for recovering businesses is the potential for massive changes in the economy of the region. Chang (2010) noted that, after the 1995 Kobe earthquake, the post-disaster economy saw a three to four-year boom in construction before settling to $10 \%$ predisaster levels. Population also shifted away from the urban core of the city and port activity dropped substantially. Industry sectors also saw a shift towards large businesses and a more service based economy. All of the aforementioned effects were found to have generally accelerated pre-disaster trends (Chang 2010). Chang and Falit-Baiamonte (2002) found that the conditions of the neighborhood were an influential factor in business recovery, typically more so than physical damage.

Alesch, Holly et al. (2001) provided several accounts from business owners dealing with the postdisaster effects. In recounting the experiences of the affected business owners several themes emerged relating to post-disaster realities. One critical theme was that many business owners believed that things would return to the pre-disaster state, failing to understand or address a changing economic reality and shifting customer bases, essentially self-limiting recovery. Other drastic changes to the economy were also discussed in Alesch, Holly et al. (2001). The changing customer base was seen as accelerating trends, such as driving customers away from small businesses to larger national firms. Business disruptions led to customers finding alternative locations to do business and maintaining the new pattern even after the disrupted businesses returned to operation.

Some businesses end up failing due to new competition (Alesch, Holly et al. 2001). After a major disaster there is substantial rebuilding and repair that needs to be done. This draws in firms from outside the damaged region. In many cases these firms are larger and better positioned to provide immediate aid, often at cheaper prices, while firms within the damaged area are still coping with clean up, repair, loss of inventory, and generally trying to get back to operational status. This hampers their ability to remain competitive in the post-disaster economy (Alesch, Holly et al. 2001). This effect would be expected to affect only select industries that typically fare better after a disaster to begin with.

A statistical analysis of how businesses viewed the state of business after a disaster was conducted in Webb, Tierney et al. (2002). In the case of hurricane Andrew, around one-third of responding businesses in South Dade County indicated that the present state of business was worse than before the disaster, while similar numbers saw decreases in employees, customers and business profits. The economic fallout from the Northridge earthquake on Santa Cruz was less destructive with only $21.5 \%$ responding that their present state of business was worse off. Lower percentages were also reported for employee, customer, and profit losses (Webb, Tierney et al. 2002). A regression analysis in Webb, Tierney et al. (2002) indicated that an owner's perception of the business climate after the disaster was a significant predictor of long-term recovery.

Alesch, Holly et al. (2001) found that a business's understanding of post-disaster changes in the economy and customer base can aid or cripple its survival chances. In examining business responses to multiple disasters, Alesch, Holly et al. (2001) found that the owners view of the post-disaster business climate was the most significant predictor of survival, a finding supported in Kroll, Landis et al. (1991). Those businesses that recognized that there was a new reality after the disaster and that they must adapt were better able to survival in a statistically significant way. 
A major economic issue post-disaster is the loss of customers as people emigrate from the affected region (Alesch, Holly et al. 2001). In the wake of the Northridge earthquake tens of thousands are believed to have left the Northridge area, while the same can be said for Dade County Florida in the wake of multiple destructive hurricanes. In the case of New Orleans, four months after Hurricane Katrina the population was $37 \%$ of the pre-disaster population of 437186 (Kates, Colten et al. 2006). As of 2016 the population has yet to return to pre-Katrina numbers.

A shrunken population means a smaller customer base for many businesses, adding to the burdens already imposed by disaster. Corey and Deitch (2011) found a significant positive correlation between the loss of customer base and business failure in the wake of hurricane Katrina, a finding further supported by Tierney (2007) and Alesch, Holly et al. (2001). The effects of a lower population can also impact the business through staffing (Tierney 2007). Employees may move away after a disaster or otherwise be unable to work due to death, injury, loss of home, or loss of transportation, among other reasons (Tierney 2007). A statistical basis for the effect on staffing can be found in Corey and Deitch (2011), which finds a significant negative correlation between staffing issues and business survival. On the opposing side, Asgary, Anjum et al. (2012) found that engagement and involvement of the staff in the recovery was a significant reducer of recovery time.

\subsection{Outside Aid}

One way businesses may mitigate the effects of a disaster is through monetary aid. Such aid is typically provided through loans from, in the case of small businesses, the Small Business Administration (SBA). Webb, Tierney et al. (2002) however, noted that there was no significant relationship between the use of post-disaster assistance and long-term recovery outcome. The authors theorized that, while households can use grants for recovery efforts, businesses typically must rely on loans. Thus it may have been the case that business owners decided to use their own savings instead of taking loans that would have to be repaid over time. It was also hypothesized that broader trends in the economy were more significant factors in recovery than post-disaster factors.

Work in Tierney and Dahlhamer (1997) and Dahlhamer and Tierney (1996) found evidence counter to the results of Webb, Tierney et al. (2002), suggesting that a relationship did exist in the case of the Northridge earthquake, though in an unexpected direction. What was found was the use of external aid including insurance, bank loans, and government loans was a significant predictor of failure. Hypotheses for this relationship included: businesses using aid were harder hit to begin with and already more likely to fail, or that resources from the aid arrived too late to be of any benefit. As with Webb, Tierney et al. (2002), the possibility that broader economic trends and the absorption of losses in lieu of the use of aid were also raised Tierney and Dahlhamer (1997). As noted previously, female owners tended to be more risk-averse, making them more receptive of financial aid (Danes, Lee et al. 2009).

In the case of Hurricane Katrina, the SBA loan program, and to some extent the Federal Emergency Management Agency (FEMA), were considered inefficient by some (Runyan 2006, Corey and Deitch 2011). The SBA requires three years of previous tax returns in order to file for a loan: however, many businesses lost all financial records as a result of the flooding due to the hurricane. Some businesses that had the required documents felt that the loan dispersal was too slow. Some businesses also felt that FEMA was pulling workers from their rebuilding efforts (Runyan 2006, Corey and Deitch 2011). The paper does not discuss how widespread these opinions were in terms of small business owners. 
Kroll, Landis et al. (1991) found that, after the Loma Prieta earthquake, Oakland and Santa Cruz were for the most part dissatisfied with FEMA services, while having a favorable view of local and state responses. In Oakland less than $5 \%$ of businesses received SBA or FEMA assistance, while $10 \%$ used SBA programs in Santa Cruz and $33 \%$ relied on FEMA. In both cases local, public and private, or state programs were used more heavily. There is little other discussion of the impact of state and local forms of aid and their effects on businesses in the literature.

Not all local government programs were adequately prepared for the earthquake. Kroll, Landis et al. (1991) did not specifically cover such cases in their survey, but did note that some government offices were facing new issues in the earthquake's aftermath without any backing policy framework; for instance, determining whether or not permits should be issued in locations that were found to be unsound geologically. Permit issues also complicated the reconstruction efforts after the 2003 Cedar Fire in San Diego County, California (Vigil 2004). Considering how dependent communities are on governmental services both pre- and post-disaster, its role in the economic recovery of a community cannot be ignored (Tierney 2007).

\section{Selected Data Sets and Scoping}

As noted in the literature, business disruption appears to be a larger factor in establishment survival than damage or demographics post-disaster. Still it is an interesting question of whether a region's socioeconomic state make it more prone to lose or gain establishments after an adverse event. Knowing this may help guide future research as to whether at-risk areas can be defined pre-disaster. A finding that demographics do matter may also help determine vulnerable populations. The latter question is not addressed herein due to a lack of data.

While the desired analysis would focus on in depth establishment failure data, data access limitations, and the precursory nature of the analysis, precluded the development or use of such a data set. Instead publically available data was obtained that could provide the information required to generate a meaningful model.

Data for the analysis on establishment closures fell into two categories: numeric data and geographic data. The numeric data consisted of the count of establishments in each Florida ZIP code, referred to as 'establishment data,' demographic and housing data from the 2000 census (U.S. Census Bureau 2000) and the 2011 American Community Survey (ACS) (U.S. Census Bureau 2011a, U.S. Census Bureau 2011b, U.S. Census Bureau 2011c, U.S. Census Bureau 2011d, U.S. Census Bureau 2011e, U.S. Census Bureau 2011f), referred to as 'demographic data', and FEMA data, referred to as 'FEMA data,' on the number of registrations, amount of money obligated, and the amount of FEMA inspected damage, among other variables.

The primary analysis units were 5-digit ZIP Code Tabulated Areas (ZCTA5), derived from U.S. Census Topologically Integrated Geographic Encoding and Referencing (TIGER) shape files for 2000 (2000 TIGER/Line Shapefiles) and 2011 (2011 TIGER/Line Shapefiles). A ZCTA5 is an approximation of the area covered by a ZIP code. Strictly speaking, ZIP codes are not geographic areas; they change over time, either through the creation of new ZIP codes or alterations to the buildings covered by a ZIP code. A ZCTA5 is merely an approximation of a geographic area that covers most of a ZIP code, given that ZIP codes are usually mixed at their "boundaries". 
Census data at the ZCTA5 level was used for the analysis. Only a select subset of variables was used in order to keep the number of variables reasonable and the results interpretable. In no way should the selected subset be considered exhaustive of all possible factors that could influence business closures. Furthermore, a fixed effect analysis was used, so any time-invariant variables were omitted. Another issue with the census data was the fact that there was no ZCTA5 level output in any of the interceding years between 2000 and 2011. This required an estimation technique which is discussed in the Methodology section.

Table 1 provides a full list of the census derived data headings. 
Table 1. Data headings for census and ACS data sets

\begin{tabular}{|c|c|c|c|}
\hline Data Heading & Units & Data Heading & Units \\
\hline ZCTA5 & $\mathrm{N} / \mathrm{A}$ & \multirow{31}{*}{$\begin{array}{l}\text { Age groups - broken down by } \\
\text { gender: } \\
\text { One heading each for } 0 \text { years } \\
\text { to } 21 \text { years } \\
22-24 \text { years } \\
25-29 \text { years } \\
30-34 \text { years } \\
35-39 \text { years } \\
40-44 \text { years } \\
45-49 \text { years } \\
50-54 \text { years } \\
55-59 \text { years } \\
60-61 \text { years } \\
62-64 \text { years } \\
65-66 \text { years } \\
67-69 \text { years } \\
70-74 \text { years } \\
75-79 \text { years } \\
80-84 \text { years } \\
85 \text { years and older }\end{array}$} & \multirow[t]{31}{*}{ Count } \\
\hline Total Housing Units & Count & & \\
\hline Occupied Housing Units & Count & & \\
\hline Vacant Housing Units & Count & & \\
\hline Owner Occupied Housing Units & Count & & \\
\hline Renter Occupied Housing Units & Count & & \\
\hline Housing Units built: & \multirow[t]{12}{*}{ Count } & & \\
\hline 1939 or earlier & & & \\
\hline 1940-1949 & & & \\
\hline 1950-1959 & & & \\
\hline 1960-1969 & & & \\
\hline 1970-1989 & & & \\
\hline 1990-1994* & & & \\
\hline 1995-1998* & & & \\
\hline 1999-March 2000* & & & \\
\hline $1990-1999 * *$ & & & \\
\hline $2000-2009 * *$ & & & \\
\hline 2010 or later** & & & \\
\hline \multirow[t]{2}{*}{ Median Household Income } & 1999 Dollars* & & \\
\hline & 2011 Dollars** & & \\
\hline Total Population & Count & & \\
\hline Ethnicity: & Count & & \\
\hline White alone & & & \\
\hline Black or African American alone & & & \\
\hline American Indian and Alaska & & & \\
\hline Native alone & & & \\
\hline Asian alone & & & \\
\hline Native Hawaiian and Other & & & \\
\hline Pacific Islander alone & & & \\
\hline Some other race alone & & & \\
\hline 2 or more races & & & \\
\hline $\begin{array}{l}\text { * For } 2000 \text { census data only } \\
\text { ** For } 2011 \text { ACS only }\end{array}$ & & & \\
\hline
\end{tabular}

The establishment data serves as a surrogate measure of business closures. While it only provides total counts it can be expected that if a disruption is substantial, then it should cause sufficient closures or openings to show up at the aggregated level. Counts of establishments by two-digit North American 
Industry Classification System (NAICS) code are also present in the establishment data, allowing for an examination of how specific industries are impacted. A rough estimate of the size of the establishment is also provided based on the number of employees. Table 2 provides a full list of the establishment data headings (U.S. Census Bureau 2002, U.S. Census Bureau 2003, U.S. Census Bureau 2004, U.S. Census Bureau 2005, U.S. Census Bureau 2006, U.S. Census Bureau 2007, U.S. Census Bureau 2008, U.S. Census Bureau 2009, U.S. Census Bureau 2010, U.S. Census Bureau 2011g, U.S. Census Bureau 2012, U.S. Census Bureau 2013).

Table 2. Data headings for Census County Business Patterns data

\begin{tabular}{|l|l|}
\hline Data Heading & Units \\
\hline ZIP code & N/A \\
\hline NAICS code & N/A \\
\hline Total number of establishments & Count \\
\hline Establishments - 1-4 employees & Count \\
\hline Establishments - 5-9 employees & Count \\
\hline Establishments - 10-19 employees & Count \\
\hline Establishments - 20-49 employees & Count \\
\hline Establishments - 50-99 employees & Count \\
\hline Establishments - 100-249 employees & Count \\
\hline Establishments - 250-499 employees & Count \\
\hline Establishments - 500-999 employees & Count \\
\hline Establishments - 1000 or more employees & Count \\
\hline
\end{tabular}

Using the establishment data means that the specific reasons for closure are unknown. As discussed in the literature some businesses close after a disaster for non-disaster related reasons so using only total counts of open businesses will include non-disaster related failures. The estimate of business size is not necessarily a good proxy for availability of resources. The establishment data only lists the number of employees at the physical location. If the business is a fast-food franchise then, while it may have few on-site employees, it may have access to franchise resources.

The demographic data focused on total population, subdivided into age, gender, and racial subgroups, as well as median household income for the ZCTA5. Housing data included total number of housing units, broken down into owned, rented, occupied, and vacant subgroups. Further divisions included year ranges for a count of units by when they were constructed.

The FEMA data contain information on the number of registrations (requests for FEMA assistance) per ZIP code, the amount of FEMA inspected damage, and the amount of money obligated by FEMA to various parties (homeowners, renters, public entities). Data was available for both home owners, renters, and public entities, though only the data for owners was utilized. While the "public entities" data may be of interest, in many cases the ZIP code corresponded to the official address of the entity, meaning the ZIP code reported may not be the ZIP code that actually experienced damage, or may only contain a portion of the damage. For instance, if damage is reported for a county school district and the ZIP code for the school district's official office is the only one listed, there is no way to know how to correctly place the reported damage and monetary amounts in the appropriate ZIP code within the 
county. The FEMA "renters" data contained the distributed dollar amounts to valid registrants, but did not include the FEMA inspected damage. The FEMA "homeowners" data was primarily used to help delineate damaged versus non-damaged regions.

Table 3 provides a full list of the FEMA data headings in the FEMA Owners data (Federal Emergency Management Agency 2013) ${ }^{4}$.

Table 3. Data headings for FEMA data on owner related registrations

\begin{tabular}{|l|l|}
\hline Data Heading & Units \\
\hline Disaster ID & N/A \\
\hline State & N/A \\
\hline County & N/A \\
\hline City & N/A \\
\hline ZIP Code & N/A \\
\hline Valid registrations & Count \\
\hline Average FEMA inspected damage & 2004 Dollars \\
\hline Total FEMA inspected registrations & Count \\
\hline Total damage & 2004 Dollars \\
\hline No FEMA inspected damage & Count \\
\hline $\begin{array}{l}\text { FEMA inspected damage between: } \\
\text { \$1-\$10 000 }\end{array}$ & Count \\
\$10 001-\$20 000 & \\
\hline G0 001-\$30 000 & \\
\hline Greater than \$30 000 & \\
\hline Total approved registrations for FEMA assistance & Count \\
\hline Repair and replace amount & 2004 Dollars \\
\hline Rental amount & 2004 Dollars \\
\hline Other needs amount & 2004 Dollars \\
\hline $\begin{array}{l}\text { Approved registrations between: } \\
\text { \$1-\$10 000 } \\
\text { \$10 001-\$25 000 } \\
\text { \$25 001 and maximum grant } \\
\text { Maximum grants }\end{array}$ & Count Dollars \\
\hline
\end{tabular}

The literature covers a wide swath of potential variables, many not included in this analysis. The reasons for focusing on demographics variables are twofold.

1. The purpose of this analysis was to explore the possibility of using ZIP code level data to determine demographic factors that may indicate a vulnerable location within a geographic area.

2. Many of the variables mentioned in the literature are difficult, if not impossible, to get predisaster. By focusing on, and establishing, demographic factors (which can be estimated

\footnotetext{
${ }^{4}$ This product uses the Federal Emergency Management Agency's API, but is not endorsed by FEMA.
} 
reasonably well) that contribute to business survival post-disaster, it may be possible to isolate certain areas and determine what makes them more likely to succumb to the effects of a disaster. This enables a focused analysis of the more pertinent factors, such as infrastructure disruptions, as well as potentially identifying vulnerable populations.

\section{Methodology}

\subsection{Primary Assumption - The "uniqueness" of the 2004 hurricane season}

Some assumptions had to be made prior to the analysis. The most important of these was that the 2004 hurricane season was a significantly different season than all those in the selected time period (2000 to 2006). The premise of the analysis is that the season was a sufficiently large shock to Florida establishments in the path of the major storms during this period that large changes could be attributable to them.

It must be acknowledged that the 2005 season did have three major events impact Florida, Hurricanes Dennis, Katrina, and Wilma. Katrina's main impact was in Louisiana, with some damage affecting Southern Florida and the Florida panhandle region, leading to the omission of those impacted regions from the analysis. A similar adjustment was made for hurricanes Dennis and Wilma where possible. It is conceivable that the 2005 season could have impacted Florida establishments at the ZIP code level and state wide meaning some of the results are attributable to the 2005 events. Unlike 2005, 2006 and 2007 saw no major hurricane events in Florida.

The years prior to 2004 did see some hurricanes produce significant damage in terms of dollar amounts-Gordon in 2000, Gabrielle in 2001, Isidore in 2002, and Bill in 2003. However, these years typically saw Florida receive only one major storm, as opposed to the four it experienced in 2004 alone. In that regard the 2004 season, and possibly the 2005 season as well, were "unique" events in the 2000's. Still a demarcation point needed to be established, and the greater abundance of data for 2004 made it the preferred choice for the analysis. Theoretically the two years could have been treated as a single event, however this would have removed the ability to account for the immediate impacts of the 2004 season, and reduced the number of usable years after the event to two, leading to less data points for regression and a reduction in the ability to quantify medium-term impacts.

Other assumptions were made based on limits of the data and requirements of the analysis. These are discussed, as the issues that required them are introduced, in subsequent sections.

\subsection{Cleaning the data sets}

Before beginning the statistical analysis, the data had to be "cleaned" in order to remove any errors. This mainly involved removing entries from the FEMA data that had incorrect or missing ZIP codes. In the case sufficient information was available to determine what the actual ZIP code should be (for example, a city name was provided and the provided location had a unique ZIP code), the ZIP code was corrected under the assumption that the city name was correct.

Entries from the establishment data related NAICS code 95 (auxiliary establishments) were dropped from industry level consideration, as NAICS 95 was removed from the NAICS code list in 2003. These establishments were redistributed in subsequent tabulations from the NAICS 95 designation to the industry of the service performed. This change potentially affected the pre-2004 trends by increasing 
establishments counted in an industry without the creation of an actual new establishment. Without knowing the specifically how the industries were redistributed it was impossible to determine which industries the establishments were distributed to between 2002 and 2003. Note that the establishment data from the census was gathered mid-March. To make the establishment data results more intuitive, the Census provided reference year for the data was reduced by one so that any changes in establishment numbers would correspond roughly to the end of the current year in the analysis.

One final data drop was a result of the selected time frame, 2000 to 2006 . Although data is available through 2016 for the census and establishment data, 2007 saw the beginning of the "Great Recession," which had a substantial economic impact on a global scale. Utilizing the post- 2006 data would mean risking the inclusion of changes in total establishments due to the economic effects of the recession, as opposed to those of the shock of the 2004 hurricane season alone. The use of a time-dummy variable to attempt to account for the recession effects is discussed in a subsequent section.

\subsection{Creation of the base map}

The first step in the analysis was creating a map of Florida that would allow a baseline for comparison. Since ZIP codes change over time, and ZCTA5 maps were found for 2000 and 2011, a means of creating unique geographic regions was required to facilitate fair comparisons. Geographical Information Software (GIS) facilitated the creation of a map of the intersecting areas of the 2000 and 2011 ZCTA5 maps. Each intersecting area, referred to as a 'ZCTA intersection', had the information of the 2000 and 2011 ZCTA5s which intersected to create it, as well as the percentage of the $2000\left(p_{00}\right)$ and $2011\left(p_{11}\right)$ ZCTA5 areas in the ZCTA intersection. These percentages were used later to distribute data into the base map.

Any areas in the 2000 and 2011 ZCTA5 maps not covered by the ZCTA intersections were removed. Firstly, the 2000 ZCTA5 map was not as refined as the 2011 ZCTA5 map. The 2000 map included significant sections of ocean in some cases where the ZCTA extended from mainland Florida to an island. This was less of an issue for the 2011 map. Using only the ZCTA intersections served to remove several areas that were not geographically correct. The other reason for not using the non-intersecting areas was that having an area that did not exist in $\mathbf{2 0 0 0}$ meant its starting population would be zero and, when incorporating the demographics data, would lead to unrealistic increases in population. The reverse situation occurred for areas present in 2000, but not in 2011.

As previously mentioned, the 2005 hurricanes were not included in the analysis, thus their corresponding data was not considered so that it could be decoupled from the 2004 season. Doing so prevented regions damaged after the 2004 season from affecting the results, as a key assumption in the analysis was that any region without damage reported for the four major storms of the 2004 hurricane season could be considered as having no damage at all in in the 2004 season and onward. Coupled with this assumption was the assumption that no ZCTA intersection was considered significantly damaged by a hurricane prior to the 2004 season. The final result was the "base map" presented in Figure 1. 


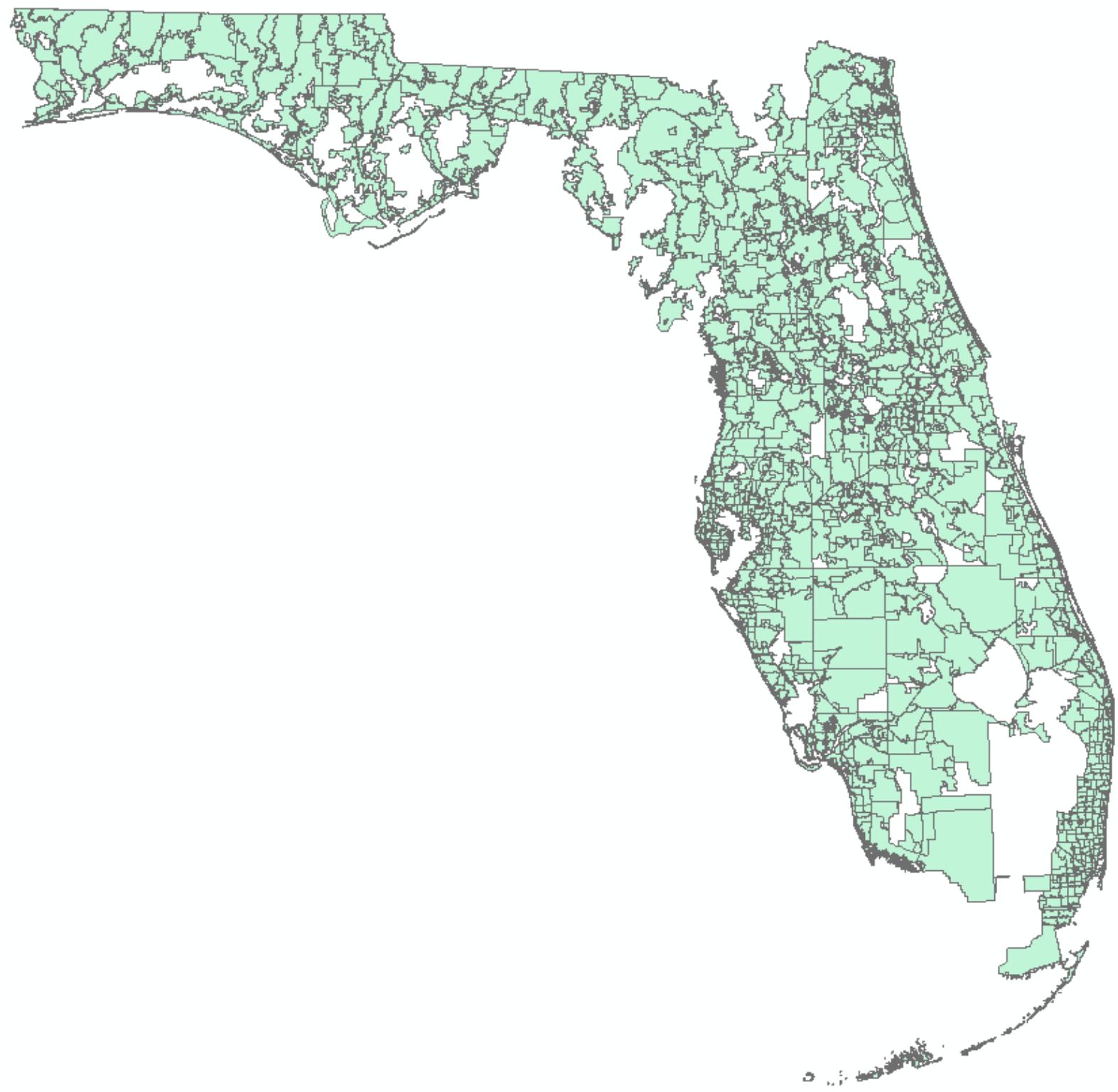

Figure 1. Map of all ZCTA intersections developed for analysis (3366 ZCTA intersections)

After generating the base map, each ZCTA intersection was designated as whether it is a coastal or interior area. This designation was accomplished by overlaying a map of Florida's coastline and selecting all ZCTA intersections that intersected it within a 100-meter tolerance to account for any differences in the two maps. Intersecting areas were given a "coastal" variable equal to one, all others were given a "coastal" variable equal to zero. Because coastal regions could reasonably be expected to receive more damage from a hurricane, due mainly to the effects of storm surges and the fact hurricanes weaken over land, it was a reasonable possibility that a coastal area would see a greater impact from storm damage, and thus a larger effect on the number of establishments, than an inland region. Explicitly accounting for the coastal variable helps remove any endogeneity it might create.

\subsection{Distribution of data to base map}


Assigning values from numeric data sets required distributing the values to the base map based on the intersecting ZCTA5s. The following method was used for the housing and demographic data, which only had values for 2000 and 2011.

1. Note that in 2000 all of the data to be distributed was entirely contained within the ZCTA of the 2000 data set, and in 2011 the data was entirely contained within the 2011 data set.

2. Distribute the $\mathbf{2 0 0 0}$ data to the base map based on the percentage area of the ZCTA5 from the data set contained within the ZCTA intersection, see Eq. 1.

3. Distribute the 2011 data to the base map based on the percentage area of the ZCTA5 from the data set contained within the ZCTA intersection, see Eq. 1.

4. Interpolate values in between assuming a linear rate of change for all variables. While a complete assumption, the lack of data in interceding years made an assumed population model necessary. Lacking justification for a specific model, linear interpolation was selected primarily for convenience. Note that all monetary variables were converted to 2011 dollars.

The establishment data was distributed according to Eq. 1 as well, however no interpolation was necessary since data was available for all years of interest.

$$
\operatorname{var}_{Z C T A}=\operatorname{var}_{00} * p_{00} *\left(1-\frac{(\text { year }-2000)}{11}\right)+\operatorname{var}_{11} * p_{11} * \frac{(\text { year }-2000)}{11}
$$

where $v a r_{Z C T A}$ is the variable of interest for a given ZCTA intersection, $v a r_{00}$ is the level of the variable for the ZCTA intersection if it were entirely determined by the 2000 ZCTA5, $v r_{11}$ is the level of the variable for the ZCTA intersection if it were entirely determined by the 2011 ZCTA5, and year is the year of interest. Variables $p_{00}$ and $p_{11}$ are the percentage of area of the 2000 and 2011 ZCTAs within the considered ZCTA intersection, respectively. Equation 1 amounts to an assumption that the 2000 ZCTA5 changes into the 2011 ZCTA5 in a linear fashion over the time frame, and that the variable in each ZCTA intersection are a weighted contribution based on the linearity assumption.

The FEMA data was distributed according to Eq. 1 as well, with the year variable being 2004 in all cases. The use of linear interpolation means that there is a built in functional form to the demographic variables which limits interpretation of the results. Causality can now only be inferred through the average growth variables defined by the 2000 and 2011 data, whereas a complete data set would allow causation to be inferred on the yearly variable levels.

\subsection{Preliminary analysis}

Initial analysis began with an examination of summary statistics for the data. Of particular interest were the pre- and post-2004 means of the data for various combinations of NAICS code, coastal, and damage indicators. The goal was to identify anomalous years or general trends that may be worth noting.

A check of whether or not 2004 should be used as a breakpoint in the time series was done before modeling the number of establishments in terms of the selected independent variables. The comparison proceeded through a difference in differences (DiD) model. A DiD model works by first breaking the data into two distinct regions-pre-treatment (coded as time equal to 0 ) and post-treatment (coded as time equal to 1)-as well as two distinct populations - those that received the treatment (coded as 
treatment equal to 1 ) and those that did not (coded as treatment equal to 0 ). Treatment refers to the application of the event of interest. While the DiD model did not account for individual fixed effects across all variables, it still provided an initial test of the uniqueness of the 2004 season. The regression in Eq. 2 aided in determining if the 2004 hurricane season was a statistically significant event (s-significant).

$$
\Delta e s t=\alpha_{0} \text { time }+\alpha_{1} \text { treatment }+\alpha_{3} \text { time\#treatment }+c
$$

where $\Delta e s t$ is the change in the total number of establishments, $\alpha_{i}$ are generic regression coefficients, \# is a symbol denoting an interaction between the variables, and $c$ is the regression constant. The change in the number of establishments was used in this instance, as it was a more direct measure of the desired value than using the total number of establishments.

Regressions required clustering by an identifier representing the ZCTA intersection (ZID) to obtain the corrected standard error estimates. There are 3366 individual clusters, so the cluster-robust standard error estimator should converge. A bootstrapping of the standard error confirmed this. Note that if $\alpha_{3}$ is $\mathrm{s}$-significant, then the effect of the treatment is s-significant. Difference in differences does not guarantee that the treatment is the only influencing factor however.

While DiD can identify whether or not a treatment has an impact, it requires that the relationship between variables meets the assumption of parallel trends. The slope of the pre-treatment treated cases must be parallel to that of the non-treated cases. If this assumption is not met then it is impossible to use DiD to infer whether or not any differences in trend after the treatment are due to the treatment itself, or the continuation of pre-treatment trends. To check for this assumption seemingly unrelated regression models (SUR) were fit to the data. All data in the treated group after the time of treatment are omitted from the regression. Data were again clustered by ZID to obtain the correct standard error estimates. Any cases with n-significant parallel trends were dropped from the DiD analysis.

For those industries not analyzed using DiD, a less rigorous graphical analysis was done to compare the slopes pre- and post-2004. The graphical approach entailed plotting a linear fit to the data in 4 distinct regions, pre-2004 without damage (Region 1), post-2004 (including 2004) without damage (Region 2), pre-2004 with damage (Region 3), and post-2004 (including 2004) with damage (Region 4). This was done for all selected industries and broken down into coastal and non-coastal ZCTA intersections. Note that it is impossible to determine the statistical significance of the trends from the graphical analysis alone.

\subsection{Model development and validation}

The first step in determining the preferred model was to determine the preliminary list of variables to use in the model. The number of establishments for a subset of available industries was selected for analysis, as well as the aggregated number of establishments across all industries. This constituted the "analysis set" for model development.

After determining whether or not 2004 was a suitable breakpoint the model for predicting the number of establishments was developed. The full data set had a panel structure, making panel regression the natural choice (Wooldridge 2002). Because there are fixed effect variables of interest, namely coastal and whether or not damage occurred, a random effects model would be preferred. Testing for consistency followed a robust Hausman test (Cameron and Trivedi 2005). In general, the test found the random effects model to be inconsistent $(p<0.001)$, making a fixed effect model more suitable. 
Serial correlations and heteroscedasticity were considered non-issues as the data fits a Large-N (3366 ZCTA intersections) Small-T (7 years) criteria which should be sufficient for cluster-robust standard errors to converge. Selection bias was also considered a non-issue as the entire population of valid ZCTA intersections was included by default, as well as full counts of all independent variables within each ZCTA intersection. Testing for the assumptions of strict exogeneity and normality of residuals required fitting the model first. In statistics strict exogeneity refers to a situation where the dependent and independent variables lack a common, but unobserved, factor resulting in correlation between an independent variable and the error term, endogeneity occurs otherwise. Endogeneity hampers interpreting coefficients as they become potentially biased and inconsistent (they converge to an incorrect value) rendering causal inference impossible. Strict exogeneity was tested by incorporating "leading" variables in the fixed effect regression and testing that their coefficients were simultaneously zero (Wooldridge 2002).

The goal of the analysis was to determine a model for the number of establishments while explicitly looking at the differences between the full factorial of combinations between the coastal and damage variables. To that end every option in the analysis set had four models developed for it. A model for coastal ZCTA intersections with and without damage, and a model for inland ZCTA intersections with and without damage. These models were then compared to determine any significant differences.

\section{Results and Discussion}

\subsection{Industry selection and definition of damaged ZCTA intersections}

Industries were selected based on the literature, and which industries were most common in Florida. Six codes were selected: 22 (Utilities), 23 (Construction), 31-33 (Manufacturing), 42 (Wholesale retail), 4445 (retail), and 53 (Real Estate and Rental and Leasing). The all industries variable includes the establishment data for all available NAICS codes. Note that the data in this case refers to establishments, that is physical locations of a business or entity. An establishment owned by a utility, for instance, may close, but the utility company itself will still exist.

The FEMA data was used to define damaged ZCTA intersections. The total dollar amount of damage from the FEMA estimates for homeowners was divided by the median income for the ZCTA intersection. This helped normalize the damage relative to the economic level of the area. For instance, a high dollar amount of damage in an area with a high median income may simply be the result of sporadic damage, while a high dollar amount of damage in a low median income area is more likely indicative of widespread damage. A ratio of 1.0 was the cutoff, with anything below that value considered nondamaged. The potential to misidentify certain regions as "not damaged" that did in fact incur serious damage existed; however, as this analysis was exploratory in nature, it was deemed sufficient as a first estimate. A more rigorous method would look at the property value of the entire ZCTA intersection and compare the damage estimates with it.

\subsection{Mean change in number of establishment results}

Table 4 contains the mean change in number of establishments (all industries) from the previous year for various analysis cases. This step was meant as an initial probe of the data. 2007 is included to show the effects of the recession on establishment growth. The small magnitude of the mean values reported 
in Table 4 is due to the fact that the combination of gains and losses over all ZCTA regions was close to zero. Note the means presented here are considered population, not sample, means.

Table 4. Mean change in number of establishments in a ZCTA intersection from previous year to listed year (standard deviation is in parenthesis) ${ }^{5}$

\begin{tabular}{|c|c|c|c|c|c|c|c|}
\hline Year & 2001 & 2002 & 2003 & 2004 & 2005 & 2006 & 2007 \\
\hline All & $\begin{array}{l}4.557 \\
(15.703)\end{array}$ & $\begin{array}{l}1.905 \\
(10.233)\end{array}$ & $\begin{array}{l}5.431 \\
(15.542)\end{array}$ & $\begin{array}{l}3.857 \\
(13.907)\end{array}$ & $\begin{array}{l}2.111 \\
(12.067)\end{array}$ & $\begin{array}{l}0.747 \\
(15.227)\end{array}$ & $\begin{array}{l}-4.258 \\
(13.666)\end{array}$ \\
\hline $\begin{array}{l}\text { All No } \\
\text { Damage }\end{array}$ & $\begin{array}{l}1.946 \\
(10.732)\end{array}$ & $\begin{array}{l}0.839 \\
(7.123)\end{array}$ & $\begin{array}{l}2.096 \\
(10.162)\end{array}$ & $\begin{array}{l}1.577 \\
(9.163)\end{array}$ & $\begin{array}{l}0.782 \\
(8.310)\end{array}$ & $\begin{array}{l}0.453 \\
(10.674)\end{array}$ & $\begin{array}{l}-1.758 \\
(9.390)\end{array}$ \\
\hline Damage & $\begin{array}{l}11.669 \\
(23.147)\end{array}$ & $\begin{array}{l}4.808 \\
(15.504)\end{array}$ & $\begin{array}{l}14.514 \\
(22.489)\end{array}$ & $\begin{array}{l}10.066 \\
(20.956)\end{array}$ & $\begin{array}{l}5.731 \\
(18.345)\end{array}$ & $\begin{array}{l}1.549 \\
(23.507)\end{array}$ & $\begin{array}{l}-11.066 \\
(19.804)\end{array}$ \\
\hline $\begin{array}{l}\text { Coastal No } \\
\text { Damage }\end{array}$ & $\begin{array}{l}3.619 \\
(15.101)\end{array}$ & $\begin{array}{l}1.237 \\
(10.839)\end{array}$ & $\begin{array}{l}3.983 \\
(15.907)\end{array}$ & $\begin{array}{l}2.616 \\
(13.149)\end{array}$ & $\begin{array}{l}0.433 \\
(12.515)\end{array}$ & $\begin{array}{l}-0.229 \\
(16.672)\end{array}$ & $\begin{array}{l}-4.254 \\
(13.654)\end{array}$ \\
\hline $\begin{array}{l}\text { Inland No } \\
\text { Damage }\end{array}$ & $\begin{array}{l}1.304 \\
(8.394)\end{array}$ & $\begin{array}{l}0.686 \\
(5.007)\end{array}$ & $\begin{array}{l}1.371 \\
(6.632)\end{array}$ & $\begin{array}{l}1.179 \\
(7.022)\end{array}$ & $\begin{array}{l}0.916 \\
(5.953)\end{array}$ & $\begin{array}{l}0.715 \\
(7.130)\end{array}$ & $\begin{array}{l}-0.800 \\
(6.872)\end{array}$ \\
\hline $\begin{array}{l}\text { Coastal } \\
\text { Damage }\end{array}$ & $\begin{array}{l}14.172 \\
(27.768)\end{array}$ & $\begin{array}{l}4.128 \\
(18.978)\end{array}$ & $\begin{array}{l}16.345 \\
(23.926)\end{array}$ & $\begin{array}{l}8.793 \\
(23.118)\end{array}$ & $\begin{array}{l}3.215 \\
(23.328)\end{array}$ & $\begin{array}{l}-2.528 \\
(27.786)\end{array}$ & $\begin{array}{l}-18.872 \\
(22.802)\end{array}$ \\
\hline $\begin{array}{l}\text { Inland } \\
\text { Damage }\end{array}$ & $\begin{array}{l}10.072 \\
(19.501)\end{array}$ & $\begin{array}{l}5.242 \\
(12.807)\end{array}$ & $\begin{array}{l}13.346 \\
(21.463)\end{array}$ & $\begin{array}{l}10.878 \\
(19.431)\end{array}$ & $\begin{array}{l}7.336 \\
(15.973)\end{array}$ & $\begin{array}{l}4.149 \\
(19.909)\end{array}$ & $\begin{array}{l}-6.088 \\
(15.741)\end{array}$ \\
\hline
\end{tabular}

What is immediately apparent in Table 4 are the results for 2002. There is an indication that some event occurred between 2001 and 2002 which had a tremendous effect on Florida establishments. Not only did the event reduce the rate of growth in Florida establishments, the effect was also statewide. It also appears in all cases that 2002 to 2003 saw a reversal of this impact to roughly pre-2003 levels of growth or better. The 2001 to 2002 event is most likely the recession of the early 2000s, which was a short lived event. The September 11, 2001 terrorist attack may also have had an impact on certain industries.

Despite the 2001-2002 recession possibly influencing trends, there is evidence for 2004 being a breakpoint, as there is a precipitous drop off after 2004 in the damaged regions. While there is a decrease in the number of establishments across all analysis combinations, the drop off in damaged regions was far more significant. Considering the 2001-2002 event seems to consistently occur across the panel, though at varying levels, it was decided to continue with the analysis as planned while noting the anomalous data and its potential effects.

Examining the 2007 results highlight the impact of the 2007 recession. It is likely that the large drop in number of establishments in 2007 contains some business failures that were due solely to the effects of the 2004 hurricane season, as the loss of establishments is greater in the damaged ZCTA intersections.

\footnotetext{
${ }^{5}$ All units in terms of number of establishments per intersection
} 
Still, it is impossible to decouple those establishments that failed due to the 2004 hurricane season alone from those that would have potentially survived if not for the combined effects of damage and the recession.

\subsection{Change in number of establishment plots}

Figure 2 contains the plot of the change in number of establishments for coastal regions, all industries, by year. The regression was broken into 4 regions, pre-2004 without damage (Region 1), post-2004 (including 2004) without damage (Region 2), pre-2004 with damage (Region 3), and post-2004 (including 2004) with damage (Region 4). This breakdown is consistent for all plots referencing "Regions".

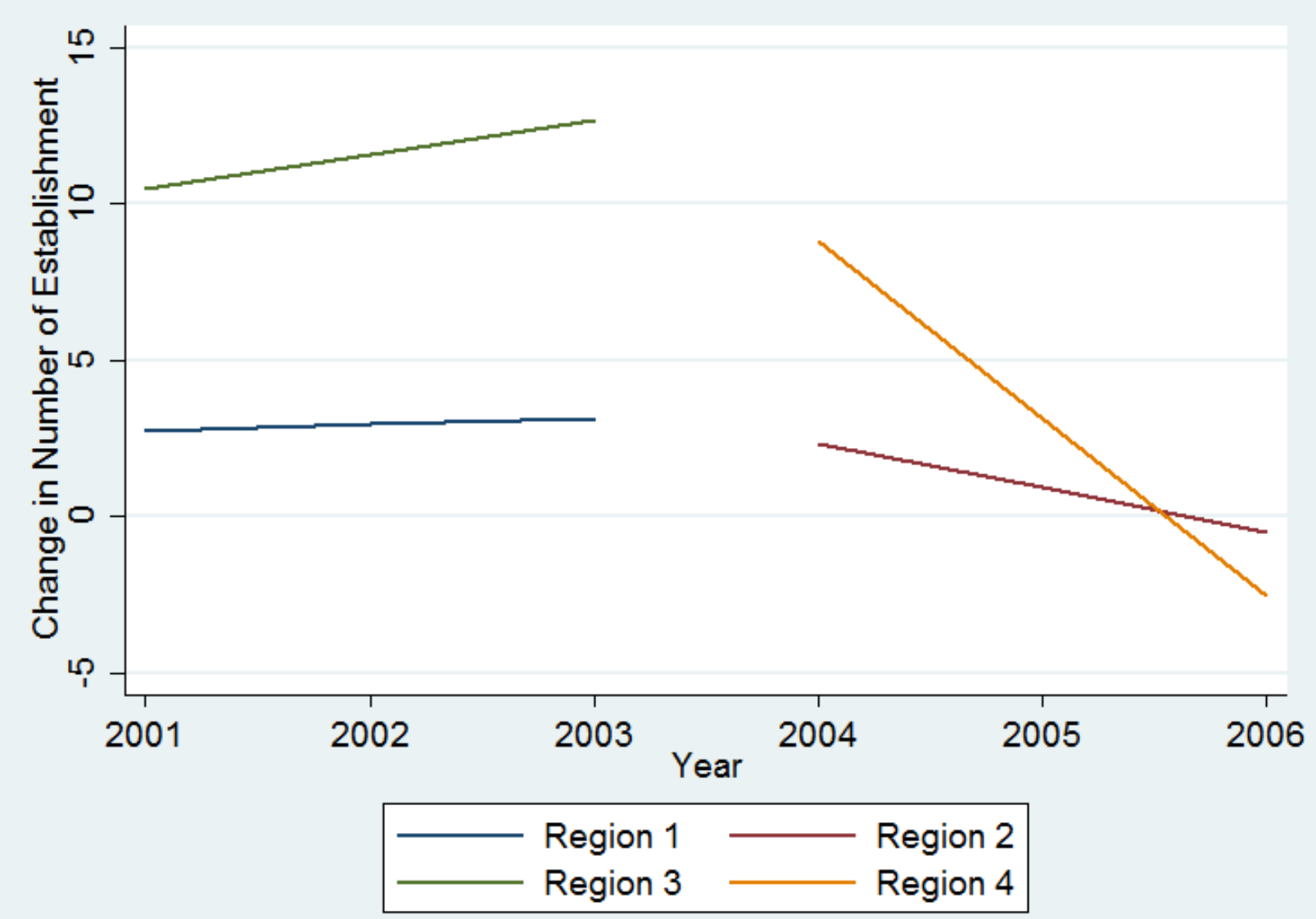

Figure 2. Plot of change in number of establishments versus time for coastal ZCTA intersections - all industries $\left(\Delta \mathbf{e s t}_{\mathrm{AII}}\right)$

What is immediately evident in Figure 2 is the drastic change in slope in the damaged ZCTA intersections. Both post-2004 trends reversed direction, however Region 4 has a much higher change in slope relative to Region 3 than does Region 2 to Region 1. The plot for the inland regions is found in Figure 3. The same general trend, not necessarily statistically equivalent, is found in Figure 3 as in Figure 2. 


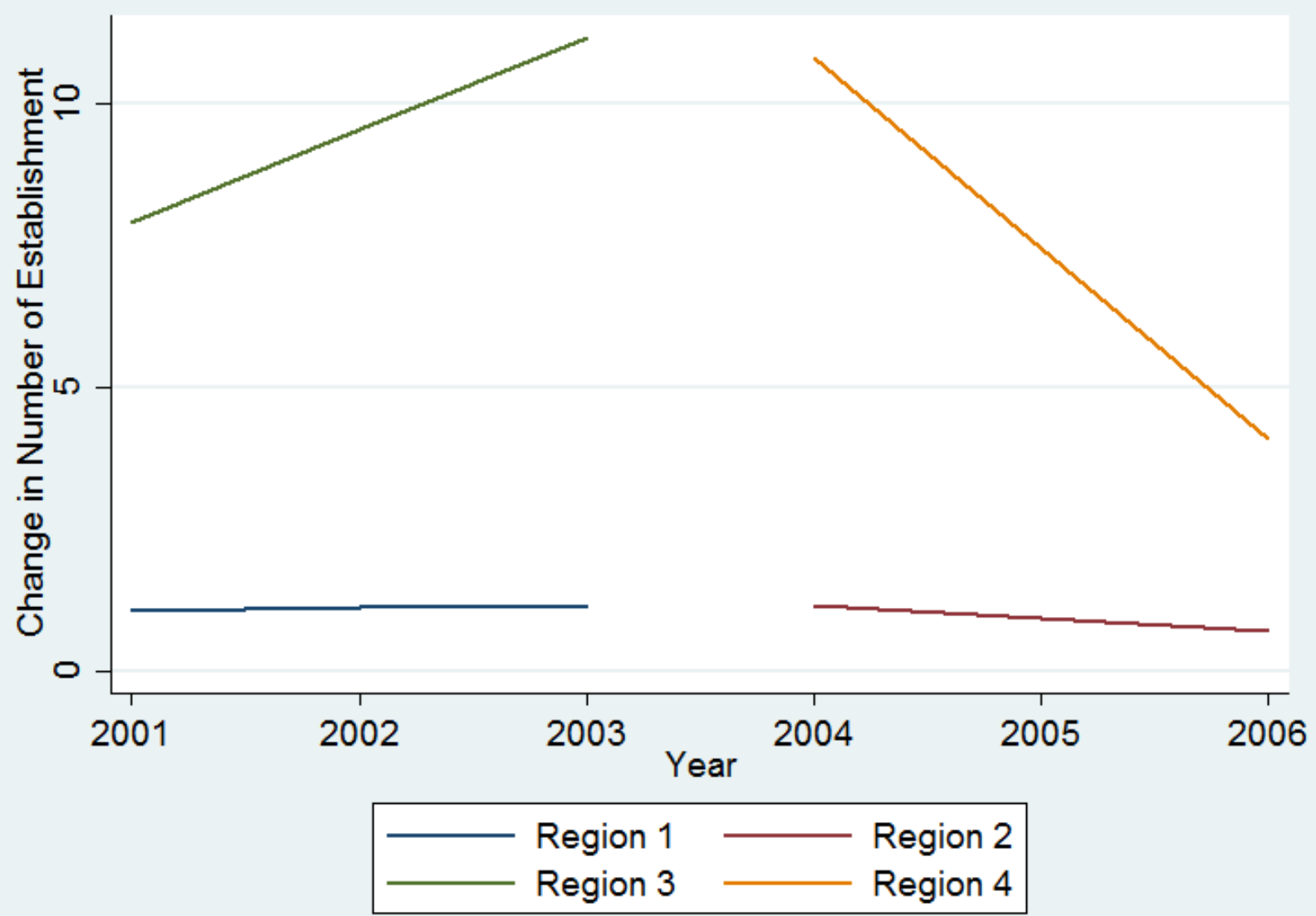

Figure 3. Plot of change in number of establishments versus time for inland ZCTA intersections - all industries $\left(\Delta \mathbf{e s t}_{\mathrm{All}}\right)$

Figure 4 plots the change in number of establishments, including the 2007 recession, for all ZCTA intersections. The figure further validates the removal of all years past 2006, as at the onset of the recession there is an extreme drop in the number of businesses that trends back towards growth over the remaining years. 


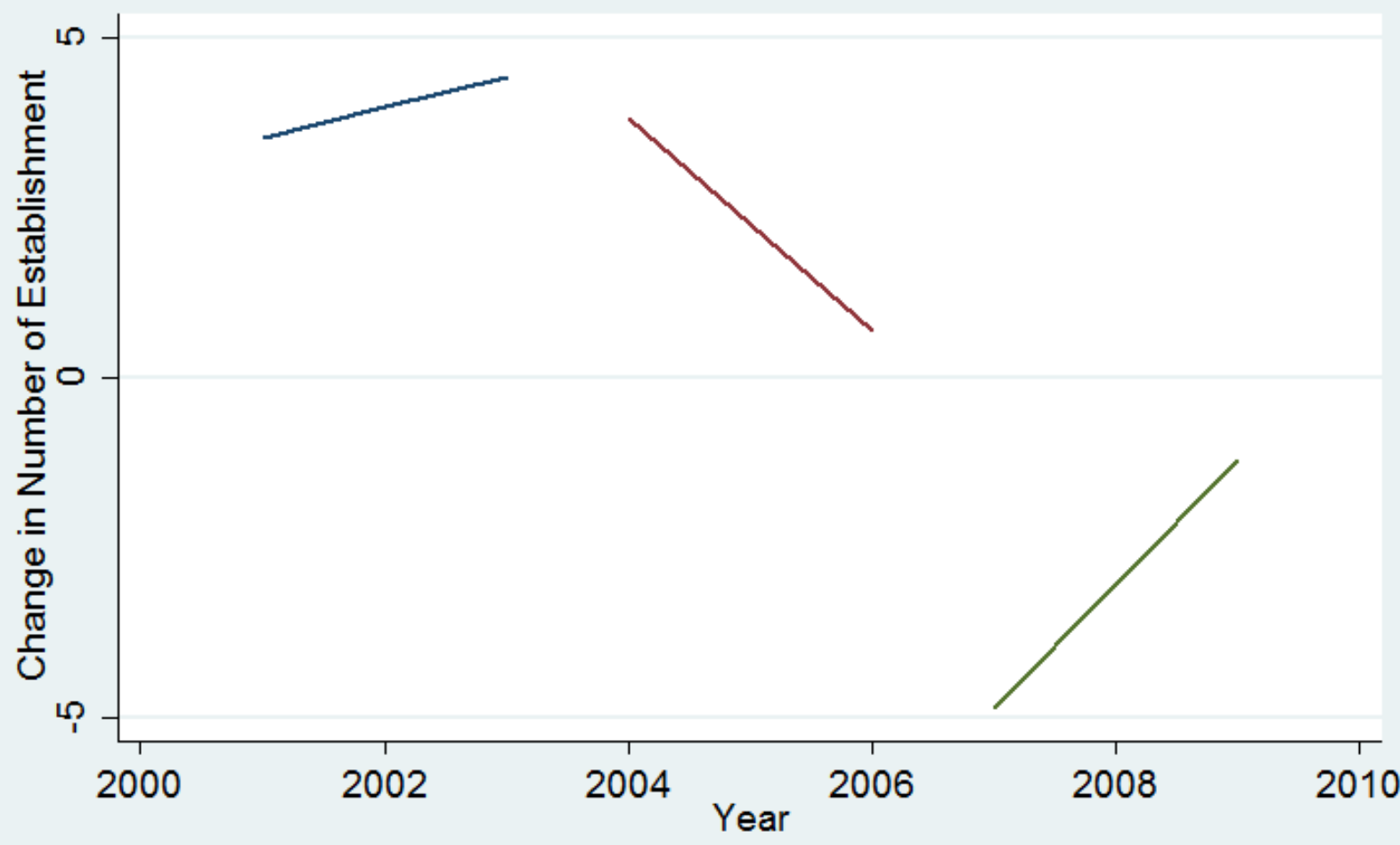

Figure 4. Plot of changing in number of establishments versus time for all ZCTA intersection - all industries $\left(\Delta\right.$ est $\left._{\text {All }}\right)$

\subsection{Difference in differences results}

Table 5 presents the SUR results of testing the parallel trends assumption for the data using fixed effects, including a break down for six of the most prevalent NAICS codes ${ }^{6}$. An n-significant interaction term means that the change in slope is not significant enough for the slopes to be considered statistically different. A p-value less than 0.05 was deemed as indicating the absence of a parallel trend, thus those variables were dropped from the DiD analysis.

${ }^{6}$ STATA's (StataCorp 2015) "regress" command was used using robust standard errors clustered on ZID 
Table 5. Results of test of parallel trends assumption for selected industries

\begin{tabular}{|c|c|c|c|c|}
\hline Variable & Industry sector & Coastal Designation & $p$-value & Parallel Trends \\
\hline \multirow[t]{2}{*}{ est } & \multirow[t]{2}{*}{ All industries } & Coastal & 0.3986 & Yes \\
\hline & & Inland & 0.0113 & No \\
\hline \multirow[t]{2}{*}{$e t_{22}$} & \multirow[t]{2}{*}{ Utilities } & Coastal & 0.025 & No \\
\hline & & Inland & 0.051 & Yes \\
\hline \multirow[t]{2}{*}{$e s t_{23}$} & \multirow[t]{2}{*}{ Construction } & Coastal & $<0.001$ & No \\
\hline & & Inland & $<0.001$ & No \\
\hline \multirow[t]{2}{*}{$e^{e s t_{31}}$} & \multirow[t]{2}{*}{ Manufacturing } & Coastal & 0.078 & Yes \\
\hline & & Inland & 0.121 & Yes \\
\hline \multirow[t]{2}{*}{$e s t_{42}$} & \multirow[t]{2}{*}{ Wholesale } & Coastal & 0.121 & Yes \\
\hline & & Inland & 0.298 & Yes \\
\hline \multirow[t]{2}{*}{$e s t_{44}$} & \multirow[t]{2}{*}{ Retail } & Coastal & 0.187 & Yes \\
\hline & & Inland & 0.891 & Yes \\
\hline \multirow[t]{2}{*}{$e t_{53}$} & \multirow[t]{2}{*}{ Real estate } & Coastal & 0.451 & Yes \\
\hline & & Inland & 0.009 & No \\
\hline
\end{tabular}

Table 5 indicates many industries lack a statistical justification of the parallel trends assumption. The results of the DiD analysis for those variables with justifiable parallel trends are presented in Table 6. 
Table 6. Results of difference in differences analysis for selected industries

\begin{tabular}{|c|c|c|c|c|c|}
\hline Variable & Industry sector & Coastal Designation & year\#PTT & $A d j-R^{2}$ & $\mathrm{p}$-value \\
\hline est & All industries & Coastal & $\begin{array}{l}-6.382 \\
(0.985)\end{array}$ & 0.0372 & $<0.001$ \\
\hline$e s t_{22}$ & Utilities & Inland & $\begin{array}{l}-0.0257 \\
(0.00567)\end{array}$ & 0.0019 & $<0.001$ \\
\hline \multirow[t]{2}{*}{$e s t_{31}$} & \multirow[t]{2}{*}{ Manufacturing } & Coastal & $\begin{array}{l}0.111 \\
(0.0792)\end{array}$ & 0.0059 & 0.161 \\
\hline & & Inland & $\begin{array}{l}-0.00550 \\
(0.0296)\end{array}$ & 0.0001 & 0.853 \\
\hline \multirow[t]{2}{*}{$e t_{42}$} & \multirow[t]{2}{*}{ Wholesale } & Coastal & $\begin{array}{l}-0.214 \\
(0.170)\end{array}$ & 0.0004 & 0.118 \\
\hline & & Inland & $\begin{array}{l}-0.0968 \\
(0.0669)\end{array}$ & 0.0039 & 0.148 \\
\hline \multirow[t]{2}{*}{$e t_{44}$} & \multirow[t]{2}{*}{ Retail } & Coastal & $\begin{array}{l}-0.935 \\
(0.221)\end{array}$ & 0.0054 & $<0.001$ \\
\hline & & Inland & $\begin{array}{l}0.104 \\
(0.0929)\end{array}$ & 0.0099 & 0.265 \\
\hline$e s t_{53}$ & Real estate & Coastal & $\begin{array}{l}-0.688 \\
(0.175)\end{array}$ & 0.0208 & $<0.001$ \\
\hline
\end{tabular}

Based on Table 6, the treatment in year 2004, assumed to be the 2004 hurricane season, has an ssignificant impact on coastal utilities overall, inland utilities, coastal real estate, and coastal retail (5\% level) industries in the negative direction. Manufacturing and wholesale retail appear to be resistant to the impacts of the 2004 hurricane season, as does inland retail.

The resilience of the manufacturing sector is expected, as manufacturing centers are generally required by code to be more robust against disasters given the economic, environmental and health damage that heavy industries can cause in the event of unexpected failure. Wholesale retail's resilience to the 2004 hurricane season is also unsurprising, as wholesale retail tends to be dominated by larger national chains, pay less for goods, and supply products to the retailers themselves. Thus any retail business trying to rebuild will rely on the wholesaler, while in areas where retail is suffering the advantages of having more resources may provide a means of absorbing the shock of the initial event.

The effect on inland utilities is surprising. The direction of the change suggests that utility establishments declined post-disaster. Massive changes to utilities were made after the 2004 and 2005 hurricane seasons in order to make them more robust (Self 2016). It should be noted however that the change in slope is only an average loss of 0.0236 establishments per year per ZCTA intersection and utilities were sparser than the other selected industries. The low $R^{2}$ is not surprising, given the premise of the analysis is that the number of establishments is based on demographic factors, and not merely a time trend.

The negative change in coastal retail matches the literature findings of retail generally suffering after a disaster. The lack of significance in the inland retail change in slope may be a product of inland regions 
being more insulated from storm surges, leaving wind (which may be less severe depending on how far inland the ZCTA intersection is) and flooding by rain as the primary means of damage. Thus damage severity, and any associated infrastructure interruptions, may generally be less for inland areas. The weakening trend in the real estate industry is also not surprising, given that major disasters may scare away potential buyers in the short term.

A graphical check was done for those variables failing the parallel trends assumptions. These plots are found in Appendix A (excluding for inland establishments - all industries, which is already found in Figure 3). Though not as strong a test, the graphical test indicates that 2004 could possibly serve as a breakpoint in the data. A few interesting trends come out of the plots in Appendix A. One general observation from the plots is that inland region growth and decline tended to be slower than coastal regions. This fact is not surprising given Florida has a healthy tourist industry built along the coastline, is a major retirement destination, and its beaches are a major draw. The greater slopes in the damaged regions after 2004 gives some justification to using 2004 as a breakpoint.

The construction industry plots in Appendix A do not match with the trend noted in the literature. Construction actually decreases statewide after 2004, with damaged regions having a much higher rate of growth in construction prior to 2004, and a much steeper drop off after. A potential explanation for the trend in construction after 2004 is the end of the 2000 to 2005 Florida housing boom (Rojas, McGuire et al. 2007), coupled with a reticence to build in heavily damaged areas. It also may have been the case that construction companies from outside the damaged regions went into damaged regions, competing with smaller construction firms that could not immediately cope with damage, driving them out of business in the years after the 2004 season. This would imply that ZCTA intersections with larger construction firms may be more robust against such changes.

The pre-2004 construction industry trend is harder to understand. While the growth in construction industries is most likely tied in with the housing boom, it is not immediately clear why regions that would eventually suffer more damage saw the largest growth. Perhaps these ZCTA intersections were underdeveloped because they were naturally prone to hurricane damage, only becoming attractive once the housing boom hit. Other hypotheses may be developed, but the reason for the greater growth pre2004 in damaged ZCTA intersections is not investigated further in this paper.

The housing boom may also explain the trends in the real estate, rental, and leasing sector (NAICS 53). The general trend is an increase up to 2003 , a jump up to 2004, followed by a decline to 2006, which suggests a timeline of increasing housing up to 2003, a jump in 2004 as people begin trying to deal with housing issues after the 2004 hurricane season, followed by a decline as the housing boom ends.

The coastal utilities show an inverse trend as that found in the DiD analysis for inland utilities, with a decrease in utility establishment growth followed by reversal of the growth trend after 2004 . It could be that changes in Florida utilities led to more establishments in potentially damaged regions, driving the trend reversal.

\subsection{Model Choice and Variable selection}

A first differences approach was used to account for fixed effects. This was done for two reasons. First, as previously stated, the change in the number of establishments was the primary concern - and difficult to discern from the establishment count at times - and a first differences approach naturally 
uses changes as the dependent variable. Second, due to the linear interpolation, the best that can be inferred is the effect of the average change of the independent variables over the selected time period on the dependent variable. First differencing reduced most of the chosen variable to the value of slope of the linear interpolation making interpretation of the coefficients more natural relative to the average changes of the regressors. There is a potential tradeoff for the conceptual gains, namely the potential loss of efficiency of the estimator. If the errors follow a random walk pattern, then a first differences model is more efficient than the within transformation used by fixed effects. However, if the errors are not serially correlated and homoscedastic, then fixed effects is more efficient.

Using the change in population density by age group $\left(\Delta a g e_{1-4}\right)$ in people $/ \mathrm{km}^{2}$ simultaneously accounted for total population and the effects of age groups and geographic area. Age groups were defined as from 0 to 20 years $\left(\Delta a g e_{1}\right), 21$ to 45 years, $\left(\Delta a g e_{2}\right), 46$ to 65 years, $\left(\Delta a g e_{3}\right)$, and 66 years and up $\left(\Delta a g e_{4}\right)$. Ethnicity was converted to a fractional form $\left(\Delta f r a c_{\text {minority }}\right)$ for use in the regression equation. This avoided a multicollinearity issue as the sum of the individual population variables was equivalent to the sum of the age variables. The interpretation of the fractional coefficient is how many additional establishments are in a ZCTA intersection based on ethnicity. An n-significant coefficient on a fractional variable is an indication that ethnicity does not play a role in the number of establishments. Gender ratio was not included in the model, as it was essentially constant throughout the selected time period.

Total Housing Units was heavily correlated with total population, $\left(R^{2}=0.9335\right)$ making it a redundant variable and warranting its exclusion. The change in housing units - occupied $(\Delta O c c)$ and units - vacant $(\Delta V a c)$ accounted for the housing parameters while the change in the fraction of occupied housing units owned $\left(\Delta \mathrm{frac}_{\text {own }}\right.$ ) was included based on similar reasoning as that behind the change fraction of minority population variable. Given that the first year in the analysis was 2000 and the Florida Building Code was implemented in March 2001, any new construction should be accounted for by this variable. The change in median household income $(\Delta \operatorname{InC})$ provided an estimate for the economic health of the ZCTA intersection's population.

A time-dummy variable $\left(\right.$ year $\left._{D}\right)$ was introduced to try and correct for effects of the individual year. This was particularly important due to the 2001-2002 recession. Including all years up to 2010 with the timedummy variable included to try and adjust for the late 2000's recession was considered. However, the potential for undue influence of those years on the data in the event that the time-dummy was unable to appropriately account for the total effect of the recession was deemed a significant enough concern to warrant their exclusion. 2004 was used as the reference year in the regression model, all timedummy coefficients are the difference between the reference year coefficient and the year coefficient.

None of the "year built" variables from the census data were used in the model. These variables would mainly inform on how much new construction or demolition occurs in a ZCTA intersection. The combination of the $\triangle O c c$ and $\triangle V a c$ variables already accounted for that information, making the inclusion of the "year built" data redundant.

\subsection{Endogeneity concerns and limitations}

Through the course of the regressions several of the models showed indications of a failure of the strict exogeneity assumption. This was problematic in that any estimated parameters from those regressions were potentially inconsistent. The cause of the endogeneity was due in some part to simultaneity in 
multiple independent variables. Simultaneity means that the dependent variable and one or more independent variables influence each other. For instance, the number of occupied houses can inform on the population, however as population grows the number of occupied houses increases. Also, the number of people in an age range corresponding to their working life could create more establishments, however working age people are often drawn to areas with jobs, thus the number of establishments may increase population.

No valid instruments could be found that effectively dealt with the endogeneity issue. Normally, lagging of the independent variables for use as instruments would be considered; however, the fact that the data are linearly interpolated cast doubt on the logic of doing so.

Ordinarily lagging regressors would resolve the issue on the conceptual grounds that future shocks should not influence past events - the population in 2005 should not dictate the total number of housing units in 2004 for instance (although growth estimates may be used by developers to decide whether or not to increase construction, so a predicted shock may cause a future variable to "reach" back becoming a sort of self-fulfilling prophesy) - but as previously noted the lagged variable is derived from an arbitrary interpolation function. Under linear interpolation this assumption is both mathematically infeasible (for this case) and logically muddled. The mathematical issue is simple, under the first differencing approach, most variables have the same value for all years, as the "change in" variables reduce to the average yearly change. This makes lagging useless as the variables are collinear.

The logical issue is that, in using linear interpolation, it is impossible to garner any idea about causation at the yearly level, as the yearly variable is based on a function of arbitrary form. Although using the estimated population density, in lieu of the "change in" variables, would resolve the mathematical issue (lagged variables would not necessarily be collinear) it is still questionable logically. If the independent variable for the individual year is known to be arbitrary, then is there any benefit in lagging to a previous year's value that is equally arbitrary? It may be justifiable to do so in some cases, but in this case it was not clear that there was a logical basis for doing so. Thus the model attempts to use the average growth in the demographic variables as a control while the year-dummies attempt to define meaningful differences between years.

Omitted variable bias (a bias in coefficient estimation due to not including a pertinent variable) was most likely a factor as well, as establishment specific information, such as amount of time closed after a disaster and infrastructure disruption were not considered. Theoretically, breaking the panel into separate subpanels by damage should alleviate this by grouping together ZCTA intersections that experienced damage.

Regression results are presented and discussed in the following section. As attempts to address endogeneity in the independent variables were unsuccessful, the parameter estimates are subject to bias and inconsistency.

\subsection{Fixed effect model results}

The first model developed for the data was a fit to the entire panel data set using first differences. This initial fit, following the form in Eq. 3, served as a check that the selected variables held some predictive power and that a fixed effects model was appropriate. 


$$
\begin{gathered}
\Delta e s t=\alpha_{1} \Delta a g e_{1}+\alpha_{2} \Delta a g e_{2}+\alpha_{3} \Delta a g e_{3}+\alpha_{4} \Delta a g e_{4}+\alpha_{5} \Delta \text { frac }_{\text {Minority }}+\alpha_{6} \Delta \operatorname{Inc} \\
+\alpha_{7} \Delta O c c+\alpha_{8} \Delta V a c+\alpha_{9} \Delta \text { frac }_{\text {own }}+\alpha_{\text {D }} \text { year }_{D}+c+u
\end{gathered}
$$

where $\alpha_{1}$ through $\alpha_{10}$ are regression coefficients, $\boldsymbol{\alpha}_{\boldsymbol{D}}$, is a vector of coefficients for the year-dummy, $c$ is a constant that corresponds to the reference year, 2004, of the time-dummy variable, and $u$ is the error term. Bear in mind that endogeneity is present in the regressions, inducing potential bias and inconsistency in the regression coefficients.

Further analysis was considered, such as examining interaction terms with year to determine the effect time has on the individual slopes of the independent variables, but with the endogeneity issue it would be impossible to truly capture the actual change.

Table 7 provides the key output for the regression for the inland ZCTA intersections with all industries included. Based on the regression there are several significant factors; however, they do not fit into a consistent pattern. For instance, three of the $\Delta a g e$ variables are significant for ZCTA intersections that experienced damage, while only two are significant for the non-damaged ones. It is tempting to infer from this result that certain age groups may be more important in determining establishment loss postdisaster, however the endogeneity issue prevents this. This also may be an indication of omitted variable bias as, assuming that the first differencing removed individual fixed effects and the yeardummy has accounted for time fixed effects, the coefficients on the continuous variables should be similar. It also may simply be a result of the endogeneity issue noted previously. Testing the coefficients for equality under an endogenous regression would provide a meaningless comparison, and was foregone.

What is interesting is the year dummy variable matches the trend that would be expected based on the timing of the hurricane season and 2001-2002 recession. The relatively small magnitude of the values is due to the fact the mean change in establishments is very close to zero, so the mean year effect is adjusting on a regression to a small mean.

Considering the constant is a measure of the year effect of 2004 on the data, the 2003 dummy indicates $s$-significantly higher $(p<0.05)$ effects, while the recession shows an s-significantly lower effect. After 2004 the difference from 2004 is significantly lower in the damaged regions for damaged ZCTA intersections, while the non-damaged regions show a less severe impact post-2004.

The general scale of the year-dummies is consistently higher for the damaged regions. This may indicate that there is some trait inherent to these ZCTA intersections which makes them more sensitive to the natural fluctuations in the business cycle. 
Table 7. Regression output for inland ZCTA intersections with all industries included

\begin{tabular}{|c|c|c|c|c|c|c|}
\hline \multirow[b]{3}{*}{ Variable } & \multirow{2}{*}{\multicolumn{3}{|c|}{$\begin{array}{c}\text { No Damage-Inland (1779 Clusters) } \\
R^{2}=0.3888 \\
F-\text { test }<0.001\end{array}$}} & \multirow{2}{*}{\multicolumn{3}{|c|}{$\begin{array}{r}\text { Damage-Inland (552 clusters) } \\
R^{2}=0.3674 \\
F-\text { test }<0.001\end{array}$}} \\
\hline & & & & & & \\
\hline & Coefficient & $\begin{array}{l}\text { Robust } \\
\text { Standard Error }\end{array}$ & $\mathrm{p}$-value & Coefficient & $\begin{array}{l}\text { Robust } \\
\text { Standard Error }\end{array}$ & $p$-value \\
\hline$\Delta a g e_{1}$ & -0.0941 & 0.0470 & 0.046 & -0.0310 & 0.0132 & 0.019 \\
\hline$\Delta a g e_{2}$ & 0.00113 & 0.0372 & 0.976 & -0.0177 & 0.0140 & 0.206 \\
\hline$\Delta a g e_{3}$ & 0.119 & 0.0303 & $<0.001$ & 0.0817 & 0.0151 & $<0.001$ \\
\hline$\Delta a g e_{4}$ & -0.0572 & 0.0467 & 0.221 & -0.0481 & 0.0227 & 0.035 \\
\hline$\Delta$ frac $_{\text {Minority }}$ & -5.090 & 2.304 & 0.027 & 1.001 & 16.348 & 0.951 \\
\hline$\Delta I n c$ & -0.000121 & 4.51E-05 & 0.008 & -0.00136 & 0.000384 & $<0.001$ \\
\hline$\Delta O c c$ & 0.0662 & 0.0653 & 0.310 & 0.0363 & 0.0224 & 0.106 \\
\hline$\Delta V a c$ & 0.00201 & 0.0447 & 0.964 & 0.0612 & 0.0139 & $<0.001$ \\
\hline$\Delta$ frac $_{\text {own }}$ & -4.343 & 1.711 & 0.011 & -0.827 & 9.957 & 0.934 \\
\hline year $_{2001}$ & 0.133 & 0.140 & 0.340 & -0.809 & 0.656 & 0.218 \\
\hline year $_{2002}$ & -0.495 & 0.109 & $<0.001$ & -5.637 & 0.576 & $<0.001$ \\
\hline year $_{2003}$ & 0.192 & 0.0955 & 0.044 & 2.468 & 0.657 & $<0.001$ \\
\hline$c^{*}$ & 0.364 & 0.107 & 0.001 & 4.464 & 0.649 & $<0.001$ \\
\hline year $_{2005}$ & -0.262 & 0.0990 & 0.008 & -3.541 & 0.607 & $<0.001$ \\
\hline year $_{2006}$ & -0.463 & 0.134 & 0.001 & -6.728 & 0.948 & $<0.001$ \\
\hline
\end{tabular}

Table 8 provides the key output for the regression for the coastal ZCTA intersections with all industries included. The same general results hold for the coastal regions as the inland regions when looking at year dummies for establishments for all industries. Again the demographics variables do not provide a viable comparison. 
Table 8. Regression output for coastal ZCTA intersections with all industries included

\begin{tabular}{|c|c|c|c|c|c|c|}
\hline \multirow[b]{3}{*}{ Variable } & \multirow{2}{*}{\multicolumn{3}{|c|}{$\begin{array}{c}\text { No Damage-Coastal (683 Clusters) } \\
R^{2}=0.3332 \\
F-\text { test }<0.001\end{array}$}} & \multirow{2}{*}{\multicolumn{3}{|c|}{$\begin{array}{c}\text { Damage-Coastal (352 Clusters) } \\
R^{2}=0.2888 \\
F-\text { test }<0.001\end{array}$}} \\
\hline & & & & & & \\
\hline & Coefficient & $\begin{array}{l}\text { Robust } \\
\text { Standard Error }\end{array}$ & $p$-value & Coefficient & $\begin{array}{l}\text { Robust } \\
\text { Standard Error }\end{array}$ & $p$-value \\
\hline$\Delta a g e_{1}$ & -0.0603 & 0.0249 & 0.016 & 0.0121 & 0.0147 & 0.413 \\
\hline$\Delta a g e_{2}$ & -0.0225 & 0.0163 & 0.167 & -0.0211 & 0.0224 & 0.345 \\
\hline$\Delta a g e_{3}$ & 0.107 & 0.0218 & $<0.001$ & 0.0566 & 0.0133 & $<0.001$ \\
\hline$\Delta a g e_{4}$ & -0.0879 & 0.0386 & 0.023 & 0.00928 & 0.0211 & 0.661 \\
\hline$\Delta f r a c_{\text {Minority }}$ & -9.380 & 6.452 & 0.147 & 56.109 & 67.963 & 0.410 \\
\hline$\Delta I n c$ & -0.000353 & 0.000101 & 0.001 & -0.00185 & 0.00113 & 0.101 \\
\hline$\Delta O c c$ & 0.0648 & 0.0287 & 0.024 & 0.0112 & 0.0251 & 0.656 \\
\hline$\Delta V a c$ & 0.0316 & 0.0223 & 0.157 & 0.0296 & 0.0158 & 0.062 \\
\hline$\Delta$ frac $_{\text {own }}$ & -9.313 & 7.519 & 0.216 & 53.538 & 102.245 & 0.601 \\
\hline year $_{2001}$ & 1.046 & 0.530 & 0.049 & 5.370 & 1.153 & $<0.001$ \\
\hline year $_{2002}$ & -1.383 & 0.350 & $<0.001$ & -4.668 & 1.030 & $<0.001$ \\
\hline year $_{2003}$ & 1.366 & 0.388 & $<0.001$ & 7.551 & 1.162 & $<0.001$ \\
\hline$c^{*}$ & 1.172 & 0.334 & $<0.001$ & 4.930 & 1.126 & $<0.001$ \\
\hline year $_{2005}$ & -2.182 & 0.386 & $<0.001$ & -5.578 & 1.102 & $<0.001$ \\
\hline year $_{2006}$ & -2.843 & 0.584 & $<0.001$ & -11.322 & 1.409 & $<0.001$ \\
\hline
\end{tabular}

All remaining regression tables can be found in Appendix B. Considering the difficulty in pulling any meaningful values out from the regressed coefficients, due to the suspected endogeneity, the year dummies are the only results of interest from Appendix B. The other potential interesting result is that the utility industry $\left(\Delta e s t_{22}\right)$ regressions indicate that the selected model does not provide a meaningful fit in all cases, complicating comparison. Utilities are therefore omitted from the remainder of the analysis.

All of the demographic variables were significant in at least 5 regressions, with the housing variables, change in housing units occupied, change in housing units vacant, and change in fraction of housing units owned, being s-significant more often than the population variables. Although the endogeneity issue makes it impossible to confirm, it may be that housing variables play a larger role in business resilience than the population variables themselves. Considering housing also informs on, and is informed by, population, this may be a surrogate effect. This is also a source of the endogeneity concern as previously described.

Values in Table 9 are read as the change in the year coefficient from the reference year (2004), while the reference year is essentially the intercept coefficient. Looking at the results by industry for nondamaged inland ZCTA intersections in Table 9, it is clear that the overall year effects differ by industry. The construction industry $\left(\Delta e s t_{23}\right)$ and real estate $\left(\Delta e s t_{53}\right)$ industry are the only ones which show a consistently s-significant negative impact after 2004 . This could be a side-effect of the end of the 
housing boom being incorporated into the year effect. Manufacturing shows no significant year effects. Wholesale retail $\left(\Delta e s t_{42}\right)$ shows better or as good performance, relative to 2004 , for all years. Retail $\left(\Delta e s t_{44}\right)$ shows a dip due to the 2001-2002 recession and an immediate drop after the 2004 hurricane season. It is possible that the effects of the 2004 hurricane season reverberated statewide in some industries, even in ZCTA intersections that were not directly impacted, or suffered only minor damage. Real estate shows a consistently negative year effect for all years except the reference year. This is counter to the housing boom in Florida prior to 2005 and suggests that there are either issues with the model, or something else occurred during the Florida housing boom that caused the real estate industry to see significant establishment losses.

It should be noted that the values for the time-dummies do not necessarily match the general trends in the DiD and graphical analysis. This is because the time-dummies adjust the number of businesses for the year while simultaneously accounting for the change in demographic variables, while the DiD and graphical analysis treated time as the only regressor, forcing it to account for all the variation in the data. Fixed effects were also not removed from the DiD and graphical analysis.

Table 9. Time-dummy regression coefficients for inland regions with experiencing no damage

\begin{tabular}{|l|r|r|r|r|r|}
\cline { 2 - 6 } \multicolumn{1}{c|}{} & \multicolumn{1}{c|}{$\Delta e s t_{23}$} & \multicolumn{1}{c|}{$\Delta e s t_{31}$} & \multicolumn{1}{c|}{$\Delta e s t_{42}$} & \multicolumn{1}{c|}{$\Delta e s t_{44}$} & \multicolumn{1}{c|}{$\Delta e s t_{53}$} \\
\hline Year & Construction & Manufacturing & Wholesale & Retail & Real Estate \\
\hline 2001 & $\mathbf{- 0 . 1 0 1 6 1}$ & -0.02249 & $\mathbf{0 . 1 0 1 4 4 9}$ & $\mathbf{0 . 0 5 2 3 3 6}$ & $\mathbf{- 0 . 1 4 2 0 5}$ \\
\hline 2002 & $\mathbf{- 0 . 1 8 3 8 6}$ & 0.008673 & $\mathbf{0 . 1 2 1 0 3 5}$ & $-\mathbf{0 . 1 3 1 2 1}$ & $-\mathbf{0 . 1 5 5 9 7}$ \\
\hline 2003 & $\mathbf{0 . 1 3 0 5 0 9}$ & -0.00372 & -0.02019 & 0.018678 & $-\mathbf{0 . 1 0 0 4 1}$ \\
\hline $2004^{*}$ & $\mathbf{0 . 1 5 7 1 7 6}$ & 0.00023 & -0.02577 & 0.029134 & $\mathbf{0 . 1 6 6 4 6 1}$ \\
\hline 2005 & $-\mathbf{0 . 1 2 2 8}$ & 0.012192 & 0.02444 & $-\mathbf{0 . 0 5 9 9 3}$ & $-\mathbf{0 . 1 7 8 2 6}$ \\
\hline 2006 & $-\mathbf{0 . 3 2 5 0 5}$ & 0.009688 & $\mathbf{0 . 0 6 0 7 8}$ & -0.0182 & $\mathbf{- 0 . 3 4 0 7 1}$ \\
\hline $\begin{array}{l}\text { * Reference year } \\
\text { S-significant at 5 \% level } \\
\text { S-significant at 10\% level }\end{array}$ \\
\hline
\end{tabular}

As seen in Table 10, the same general pattern from Table 9 holds for inland regions damaged in the 2004 Atlantic hurricane season with the exception of one. Wholesale retail $\left(\Delta e s t_{42}\right)$ has no significant year effects prior to 2004 and the post-2004 shows a negative trend in 2005. As previously noted, the retail industry $\left(\Delta e s t_{44}\right)$ not experiencing decline runs counter to the literature, but may be due to inland regions being subject to less flooding. 
Table 10. Time-dummy regression coefficients for inland regions experiencing damage

\begin{tabular}{|l|r|r|r|r|r|}
\cline { 2 - 6 } \multicolumn{1}{c|}{} & \multicolumn{1}{c|}{$\Delta e s t_{23}$} & \multicolumn{1}{c|}{$\Delta e s t_{31}$} & \multicolumn{1}{c|}{$\Delta e s t_{42}$} & \multicolumn{1}{c|}{$\Delta e s t_{44}$} & \multicolumn{1}{c|}{$\Delta e s t_{53}$} \\
\hline Year & Construction & Manufacturing & Wholesale & Retail & Real Estate \\
\hline 2001 & $\mathbf{- 0 . 8 1 7 5 3}$ & 0.019698 & 0.121994 & 0.18329 & $\mathbf{- 1 . 1 4 1 1 4}$ \\
\hline 2002 & $\mathbf{- 1 . 4 6 4 7 7}$ & 0.041077 & 0.172071 & $-\mathbf{0 . 5 2 6 2 8}$ & $\mathbf{- 1 . 2 7 2 5 5}$ \\
\hline 2003 & $\mathbf{2 . 5 1 4 0 6 3}$ & -0.08727 & -0.17025 & 0.202182 & $-\mathbf{0 . 6 7 6 9 8}$ \\
\hline $2004^{*}$ & $\mathbf{1 . 3 8 1 2 5 9}$ & 0.02246 & 0.16508 & $\mathbf{0 . 0 1 2 0 8 2}$ & $\mathbf{1 . 1 8 6 0 7 1}$ \\
\hline 2005 & $\mathbf{- 1 . 3 8 6 4 8}$ & -0.04798 & $-\mathbf{0 . 3 2 8 1}$ & 0.074966 & $-\mathbf{0 . 8 6 6 0 9}$ \\
\hline 2006 & $\mathbf{- 3 . 3 0 2 3 9}$ & 0.045739 & 0.035447 & 0.10305 & $\mathbf{- 2 . 1 0 6 2 2}$ \\
\hline $\begin{array}{l}\text { * Reference year } \\
\text { S-significant at 5 \% level } \\
\text { S-significant at 10\% level }\end{array}$ \\
\hline
\end{tabular}

Table 11 and Table 12 contain the year-dummies by industry for the coastal regions without and with damage, respectively. The results of Table 11 are very similar to that of Table 9, indicating that the timetrends for non-damage ZCTA intersections are roughly similar across coastal and inland regions, with the potential exception of the retail industry. This provides some indication that breaking the panel into subpanels preserved the overall time-trend directions, but not necessarily the size of the effect. Table 12 shows that the general trend from the inland damaged regions in Table 10 is the same with the exception of the retail industry $\left(\Delta e s t_{44}\right)$, which displays the trend expected in the literature of a larger negative impact post-disaster.

Table 11. Time-dummy regression coefficients for coastal regions not experiencing damage

\begin{tabular}{|l|r|r|r|r|r|}
\cline { 2 - 6 } \multicolumn{1}{c|}{} & \multicolumn{1}{c|}{$\Delta e s t_{23}$} & \multicolumn{1}{c|}{$\Delta e s t_{31}$} & \multicolumn{1}{c|}{$\Delta e s t_{42}$} & \multicolumn{1}{c|}{$\Delta e s t_{44}$} & \multicolumn{1}{c|}{$\Delta e s t_{53}$} \\
\hline Year & Construction & Manufacturing & Wholesale & Retail & Real Estate \\
\hline 2001 & -0.16795 & $\mathbf{- 0 . 2 1 2 0 4}$ & $\mathbf{0 . 2 5 7 2 9 9}$ & 0.177367 & $\mathbf{- 0 . 3 2 6 7 4}$ \\
\hline 2002 & $\mathbf{- 0 . 4 1 6 6 2}$ & -0.07274 & 0.068216 & -0.15521 & $\mathbf{- 0 . 4 3 9 7 1}$ \\
\hline 2003 & $\mathbf{0 . 4 3 5 4}$ & -0.03205 & $-\mathbf{0 . 2 5 8 1 9}$ & 0.058077 & -0.15654 \\
\hline $2004 *$ & $\mathbf{0 . 4 7 2 5 0 4}$ & 0.025332 & 0.000116 & 0.010131 & $\mathbf{0 . 5 9 8 1 5 5}$ \\
\hline 2005 & $\mathbf{- 0 . 6 1 4 3 2}$ & -0.05816 & $-\mathbf{0 . 1 8 4 4 4}$ & -0.10602 & $\mathbf{- 0 . 6 3 9 6 9}$ \\
\hline 2006 & $\mathbf{- 0 . 8 7 6 9 8}$ & -0.02098 & 0.117097 & -0.16434 & $\mathbf{- 1 . 5 0 5 6 2}$ \\
\hline
\end{tabular}

* Reference year

S-significant at $5 \%$ level

S-significant at $10 \%$ level 
Table 12. Time-dummy regression coefficients for coastal regions experiencing damage

\begin{tabular}{|l|r|r|r|r|r|}
\cline { 2 - 6 } \multicolumn{1}{c|}{} & \multicolumn{1}{c|}{$\Delta e s t_{23}$} & \multicolumn{1}{c|}{$\Delta e s t_{31}$} & \multicolumn{1}{c|}{$\Delta e s t_{42}$} & \multicolumn{1}{c|}{$\Delta e s t_{44}$} & \multicolumn{1}{c|}{$\Delta e s t_{53}$} \\
\hline Year & Construction & Manufacturing & Wholesale & Retail & Real Estate \\
\hline 2001 & -0.25489 & -0.09216 & $\mathbf{0 . 6 3 8 1 2 6}$ & $\mathbf{1 . 1 2 9 3 9 4}$ & $\mathbf{- 1 . 4 5 7 0 8}$ \\
\hline 2002 & $\mathbf{- 1 . 7 1 7 7 4}$ & -0.05104 & $\mathbf{0 . 6 4 3 3}$ & $-\mathbf{0 . 6 1 0 1 5}$ & $\mathbf{- 2 . 2 2 1 6 4}$ \\
\hline 2003 & $\mathbf{3 . 2 2 5 7 3 3}$ & -0.2271 & -0.45634 & 0.395132 & $\mathbf{- 1 . 5 3 5 2 5}$ \\
\hline $2004^{*}$ & $\mathbf{2 . 3 2 0 7 4 6}$ & -0.0889 & -0.21354 & 0.132834 & $\mathbf{2 . 7 5 9 5 7 3}$ \\
\hline 2005 & $\mathbf{- 2 . 0 4 7 0 4}$ & -0.03296 & -0.01829 & $-\mathbf{0 . 8 2 9 2}$ & $\mathbf{- 3 . 0 4 1 1 8}$ \\
\hline 2006 & $\mathbf{- 4 . 6 4 1 5 6}$ & 0.256315 & 0.088345 & $\mathbf{- 1 . 3 7 7 7 1}$ & $\mathbf{- 5 . 4 8 6 0 4}$ \\
\hline $\begin{array}{l}\text { * Reference year } \\
\text { S-significant at 5 \% level } \\
\text { S-significant at 10\% level }\end{array}$ & & & & \\
\hline
\end{tabular}

\section{Conclusion and Future Work}

Business resilience is a key component of overall community resilience. Businesses are crucial to the rebuilding effort of a community's economy. In light of this it is important to understand what determines if a business survives. The literature review provides a large collection of factors that have been shown to consistently impact business survival, including the size of the establishment and industry, however the actual interruption of business operations is often found to be a large factor. In light of this an attempt to determine the pertinent demographic factors affecting business survival was undertaken using the 2004 Atlantic hurricane season and its impacts on Florida at the ZIP code level.

Attempting to generalize the effects on businesses across an entire state with limited data raised challenges. The need for interpolation rendered the demographic data used in the regression a measure of average growth from 2000 to 2011, instead of using yearly observed populations. This assumption limited what could be done with the analysis. A DiD analysis, paired with a less rigorous graphical analysis, provided evidence that 2004 was indeed a breakpoint in the data. Going forward with the regression an issue of endogeneity was discovered in the data. Lacking a justifiable way to treat the endogeneity, no valid instruments could be found. Any regression coefficients would be the result of an inconsistent estimator under fixed effects. The regressions were performed regardless as a cursory analysis, while acknowledging that any results would more than likely be inconsistent.

While the results on the demographic variables were not meaningful, the time-invariant dummy variable results indicated that there is reason to believe that the effects of not only large disaster, but also other significant economic events, can be measured at a ZIP code level over a large region. Confounding factors and endogeneity made direct identification of causal effects impossible. However, this paper does serve as an initial guide at what needs to be examined in future research. For statewide disasters, an examination at the ZIP code level similar to this one, but with more data, may indicate which region's demographics make it more prone to negative impacts from disasters. Future work should focus on identifying other large scale disasters where more complete demographic data can be obtained and applying a similar approach to the one in this paper to detect critical demographic variables for resilience. Also, a check of the predictive power of the model should be done, as bias may render 
interpreting coefficients impossible, but not necessarily render the predictive power of the model meaningless.

Future work will involve using the guidance of the literature review to determine data collection for a more in depth study of the factors influencing business survivability in the wake of disaster. The model itself will also be tested to see whether or not it has predictive capability. While the interpretation of the coefficients may be impossible due to the endogeneity, it may still be possible that the model, or a variation of the model, may hold significant predictive power. 


\section{References}

2000 Tiger/Line Shapefiles [machine-readable data files]. retrieved from <http://www.fgdl.org/metadataexplorer/explorer.jsp> prepared by the U.S. Census Bureau, Washington, DC, 2000

2011 Tiger/Line Shapefiles [machine-readable data files]. retrieved from <http://www.fgdl.org/metadataexplorer/explorer.jsp> prepared by the U.S. Census Bureau, Washington, DC, 2011

Aldrisch, H. and E. Auster (1986). "Even dwarfs started small: liabilities of size and age and their strategies implications." Res. Organ. Behav 8: 165-198.

Alesch, D. J., J. N. Holly, E. Mittler and R. Nagy (2001). Organizations at risk: What happens when small businesses and not-for-profits encounter natural disasters, Public Entity Risk Institute PERI.

Asgary, A., M. I. Anjum and N. Azimi (2012). "Disaster recovery and business continuity after the 2010 flood in Pakistan: Case of small businesses." International journal of disaster risk reduction 2: 46-56.

Barman, S. D., S. C. Majumder and S. Sarker (2012). "Effecting Factors of Disaster Loss Recovery Plan (DLRP) for Small Scale Business (SCB) in the Coastal Area of Bangladesh." Iğdır Univ J Inst Sci \& Tech 2(4): 67-72.

Basker, E. and J. Miranda (2012). Taken by storm: Business survival in the aftermath of Hurricane Katrina, Citeseer.

Boarnet, M. G. (1996). "Business losses, transportation damage and the Northridge earthquake." University of California Transportation Center.

Boden, R. J. and A. R. Nucci (2000). "On the survival prospects of men's and women's new business ventures." Journal of business venturing 15(4): 347-362.

Cameron, A. C. and P. K. Trivedi (2005). Microeconometrics: methods and applications, Cambridge university press.

Cavanaugh, M. L. (2000). The Loma Prieta Earthquake and Hurricane Andrew: a comparative study of disaster preparedness activities.

Chang, S. E. (1998). "Direct economic impacts." Ch 6: 75-94.

Chang, S. E. (2000). "Transportation performance, disaster vulnerability, and long-term effects of earthquakes." Second EuroConference on Global Change and Catastrophic Risk Management. Laxenburg, Austria.

Chang, S. E. (2010). "Urban disaster recovery: a measurement framework and its application to the 1995 Kobe earthquake." Disasters 34(2): 303-327.

Chang, S. E. and A. Falit-Baiamonte (2002). "Disaster vulnerability of businesses in the 2001 Nisqually earthquake." Global Environmental Change Part B: Environmental Hazards 4(2): 59-71.

Cole, C., R. Corbett and K. McCullough (2005). "2004 hurricane losses: testing the lessons learned from Hurricane Andrew." CPCU eJournal 58(3): 1-9.

Corey, C. M. and E. A. Deitch (2011). "Factors affecting business recovery immediately after Hurricane Katrina." Journal of Contingencies and crisis management 19(3): 169-181. 
Dahlhamer, J. M. and M. J. D'Souza (1995). "Determinants of business disaster preparedness in two US metropolitan areas."

Dahlhamer, J. M. and K. J. Tierney (1996). "Winners and losers: predicting business disaster recovery outcomes following the Northridge earthquake."

Dahlhamer, J. M. and K. J. Tierney (1998). "Rebounding from disruptive events: Business recovery following the Northridge earthquake." Sociological Spectrum 18(2): 121-141.

Danes, S. M., J. Lee, S. Amarapurkar, K. Stafford, G. Haynes and K. E. Brewton (2009). "Determinants of family business resilience after a natural disaster by gender of business owner." Journal of Developmental Entrepreneurship 14(04): 333-354.

Dash, N., B. H. Morrow, J. Mainster and L. Cunningham (2007). "Lasting effects of Hurricane Andrew on a working-class community." Natural Hazards Review 8(1): 13-21.

Elizabeth, C. and S. Baines (1998). "Does gender affect business 'performance'? A study of microbusinesses in business services in the UK." Entrepreneurship \& Regional Development 10(2): 117135.

Enarson, E. (2010). Gender, CRC Press, Boca Raton, FL: 123-154.

Fairlie, R. W. and A. M. Robb (2009). "Gender differences in business performance: evidence from the Characteristics of Business Owners survey." Small Business Economics 33(4): 375-395.

Federal Emergency Management Agency (2013); Housing Assistance Data Owners - V1; using FEMA API <https://www.fema.gov/openfema-dataset-housing-assistance-data-owners-v1>, (September 23, 2016)

Federal Emergency Management Agency (2005); FEMA Mapping and Analysis Center: 2005 Named Tropical Storms/Hurricanes. <

https://web.archive.org/web/20080929053918/http://www.gismaps.fema.gov/2005pages/2005storms. shtm> (September 23, 2016)

Fort, T. C., J. Haltiwanger, R. S. Jarmin and J. Miranda (2013). "How firms respond to business cycles: The role of firm age and firm size." IMF Economic Review 61(3): 520-559.

Gordon, P., H. W. Richardson and B. Davis (1998). Transport-related impacts of the Northridge earthquake, National Emergency Training Center.

Headd, B. (2003). "Redefining business success: Distinguishing between closure and failure." Small Business Economics 21(1): 51-61.

Jarmin, R. S., C. Krizan and A. Luque (2014). "Owner Characteristics and Firm Performance During the Great Recession." US Census Bureau Center for Economic Studies Paper No. CES-WP-14-36.

Jones-DeWeever, A. (2007). "Gender, Race, and Class Disadvantage Pre-and Post-Katrina." Women's Rts. L. Rep. 28: 21.

Kalleberg, A. L. and K. T. Leicht (1991). "Gender and organizational performance: Determinants of small business survival and success." Academy of management journal 34(1): 136-161.

Kates, R. W., C. E. Colten, S. Laska and S. P. Leatherman (2006). "Reconstruction of New Orleans after Hurricane Katrina: a research perspective." Proceedings of the National Academy of Sciences 103(40): 14653-14660.

Kroll, C. A., J. D. Landis, Q. Shen and S. Stryker (1991). "Economic impacts of the Loma Prieta earthquake: a focus on small business." 
Marshall, M. I., L. S. Niehm, S. B. Sydnor and H. L. Schrank (2015). "Predicting small business demise after a natural disaster: an analysis of pre-existing conditions." Natural Hazards 79(1): 331-354.

Mendonça, D., E. E. Lee and W. A. Wallace (2004). Impact of the 2001 World Trade Center attack on critical interdependent infrastructures. Systems, Man and Cybernetics, 2004 IEEE International Conference on, IEEE.

Nigg, J. M. (1995). "Business disruption due to earthquake-induced lifeline interruption."

Reed, D. A., M. D. Powell and J. M. Westerman (2010). "Energy infrastructure damage analysis for hurricane Rita." Natural Hazards Review 11(3): 102-109.

Rojas, G. M., S. T. McGuire, S. Ivey and T. Durrenberger (2007). "The Florida Housing Boom." Florida Focus 3(2): 1-16.

Rosa, P., S. Carter and D. Hamilton (1996). "Gender as a determinant of small business performance: Insights from a British study." Small business economics 8(6): 463-478.

Runyan, R. C. (2006). "Small business in the face of crisis: identifying barriers to recovery from a Natural Disaster1." Journal of Contingencies and Crisis Management 14(1): 12-26.

Schrank, H. L., M. I. Marshall, A. Hall-Phillips, R. F. Wiatt and N. E. Jones (2013). "Small-business demise and recovery after Katrina: rate of survival and demise." Natural hazards 65(3): 2353-2374.

Self, F. (2016, June 10, 2016). "Utilty Service \& Hurricanes: What You Need To Know." Retrieved September 2, 2016, from http://www.flabusinesslaw.com/government-and-regulatory-2/utility-servicehurricanes-what-you-need-to-know/.

Shinozuka, M., A. Rose and R. T. Eguchi (1998). "Engineering and socioeconomic impacts of earthquakes."

Tierney, K. J. (1995). "Impacts of recent US disasters on businesses: the 1993 midwest floods and the 1994 Northridge Earthquake."

Tierney, K. J. (1997). "Business impacts of the Northridge earthquake." Journal of Contingencies and Crisis Management 5(2): 87-97.

Tierney, K. J. (2007). Businesses and disasters: vulnerability, impacts, and recovery. research, Springer: $275-296$.

Tierney, K. J. and J. M. Dahlhamer (1997). "Business disruption, preparedness and recovery: Lessons from the Northridge earthquake."

Tierney, K. J. and G. R. Webb (2001). "Business vulnerability to earthquakes and other disasters."

U.S. Census Bureau; Census (2000), Summary File 1, Table DP-1; generated by Stanley Gilbert, using American FactFinder <http://factfinder2.census.gov>; (August 15, 2016)

U.S. Census Bureau. (2002). Florida--2000 County Business Patterns (NAICS). Retrieved from <http://www.census.gov/data/datasets/2000/econ/cbp/2000-cbp.html>

U.S. Census Bureau. (2003). Florida--2001 County Business Patterns (NAICS). Retrieved from <http://www.census.gov/data/datasets/2001/econ/cbp/2001-cbp.html>

U.S. Census Bureau. (2004). Florida--2002 County Business Patterns (NAICS). Retrieved from <http://www.census.gov/data/datasets/2002/econ/cbp/2002-cbp.html> 
U.S. Census Bureau. (2005). Florida--2003 County Business Patterns (NAICS). Retrieved from <http://www.census.gov/data/datasets/2003/econ/cbp/2003-cbp.html>

U.S. Census Bureau. (2006). Florida--2004 County Business Patterns (NAICS). Retrieved from <http://www.census.gov/data/datasets/2004/econ/cbp/2004-cbp.html>

U.S. Census Bureau. (2007). Florida--2005 County Business Patterns (NAICS). Retrieved from <http://www.census.gov/data/datasets/2005/econ/cbp/2005-cbp.html>

U.S. Census Bureau. (2008). Florida--2006 County Business Patterns (NAICS). Retrieved from <http://www.census.gov/data/datasets/2006/econ/cbp/2006-cbp.html>

U.S. Census Bureau. (2009). Florida--2007 County Business Patterns (NAICS). Retrieved from <http://www.census.gov/data/datasets/2007/econ/cbp/2007-cbp.html>

U.S. Census Bureau. (2010). Florida--2008 County Business Patterns (NAICS). Retrieved from <http://www.census.gov/data/datasets/2008/econ/cbp/2008-cbp.html>

U.S. Census Bureau; American Community Survey, (2011a) 5-year Estimates, Table B01001; generated by Stanley Gilbert; using American FactFinder <http://factfinder2.census.gov>; (August 15, 2016)

U.S. Census Bureau; American Community Survey, (2011b) 5-year Estimates, Table B02001; generated by Stanley Gilbert; using American FactFinder <http://factfinder2.census.gov>; (August 15, 2016)

U.S. Census Bureau; American Community Survey, (2011c) 5-year Estimates, Table B25001; generated by Stanley Gilbert; using American FactFinder <http://factfinder2.census.gov>; (August 15, 2016)

U.S. Census Bureau; American Community Survey, (2011d) 5-year Estimates, Table B25002; generated by Stanley Gilbert; using American FactFinder <http://factfinder2.census.gov>; (August 15, 2016)

U.S. Census Bureau; American Community Survey, (2011e) 5-year Estimates, Table B25034; generated by Stanley Gilbert; using American FactFinder <http://factfinder2.census.gov>; (August 15, 2016)

U.S. Census Bureau; American Community Survey, (2011f) 5-year Estimates, Table B25003; generated by Stanley Gilbert; using American FactFinder <http://factfinder2.census.gov>; (August 15, 2016)

U.S. Census Bureau. (2011g). Florida--2009 County Business Patterns (NAICS). Retrieved from <http://www.census.gov/data/datasets/2009/econ/cbp/2009-cbp.html>

U.S. Census Bureau. (2012). Florida--2010 County Business Patterns (NAICS). Retrieved from <http://www.census.gov/data/datasets/2010/econ/cbp/2010-cbp.html>

U.S. Census Bureau. (2013). Florida--2011 County Business Patterns (NAICS). Retrieved from <http://www.census.gov/data/datasets/2011/econ/cbp/2011-cbp.html>

Vaishnavi, S., K. Connor and J. R. Davidson (2007). "An abbreviated version of the Connor-Davidson Resilience Scale (CD-RISC), the CD-RISC2: Psychometric properties and applications in psychopharmacological trials." Psychiatry research 152(2): 293-297.

Vigil, J. (2004). Permit dispute slows Julian fire victims' rebuilding. San Diego Union Tribune. San Diego. Wasileski, G., H. Rodríguez and W. Diaz (2011). "Business closure and relocation: a comparative analysis of the Loma Prieta earthquake and Hurricane Andrew." Disasters 35(1): 102-129.

Webb, G. R., K. J. Tierney and J. M. Dahlhamer (2000). "Businesses and disasters: Empirical patterns and unanswered questions." Natural Hazards Review 1(2): 83-90. 
Webb, G. R., K. J. Tierney and J. M. Dahlhamer (2002). "Predicting long-term business recovery from disaster: a comparison of the Loma Prieta earthquake and Hurricane Andrew." Global Environmental Change Part B: Environmental Hazards 4(2): 45-58.

Wooldridge, J. M. (2002). "Econometric analysis of cross section and panel data." Cambridge, MA: Massachusetts Institute of Technology.

Zhang, Y., M. K. Lindell and C. S. Prater (2009). "Vulnerability of community businesses to environmental disasters." Disasters 33(1): 38-57.

Zolin, R. and F. Kropp (2007). "How surviving businesses respond during and after a major disaster." Journal of Business Continuity \& Emergency Planning 1(2): 183-199. 
Appendix A. Trend plots of change in the number of establishments over time for industries failing the parallel trends assumption

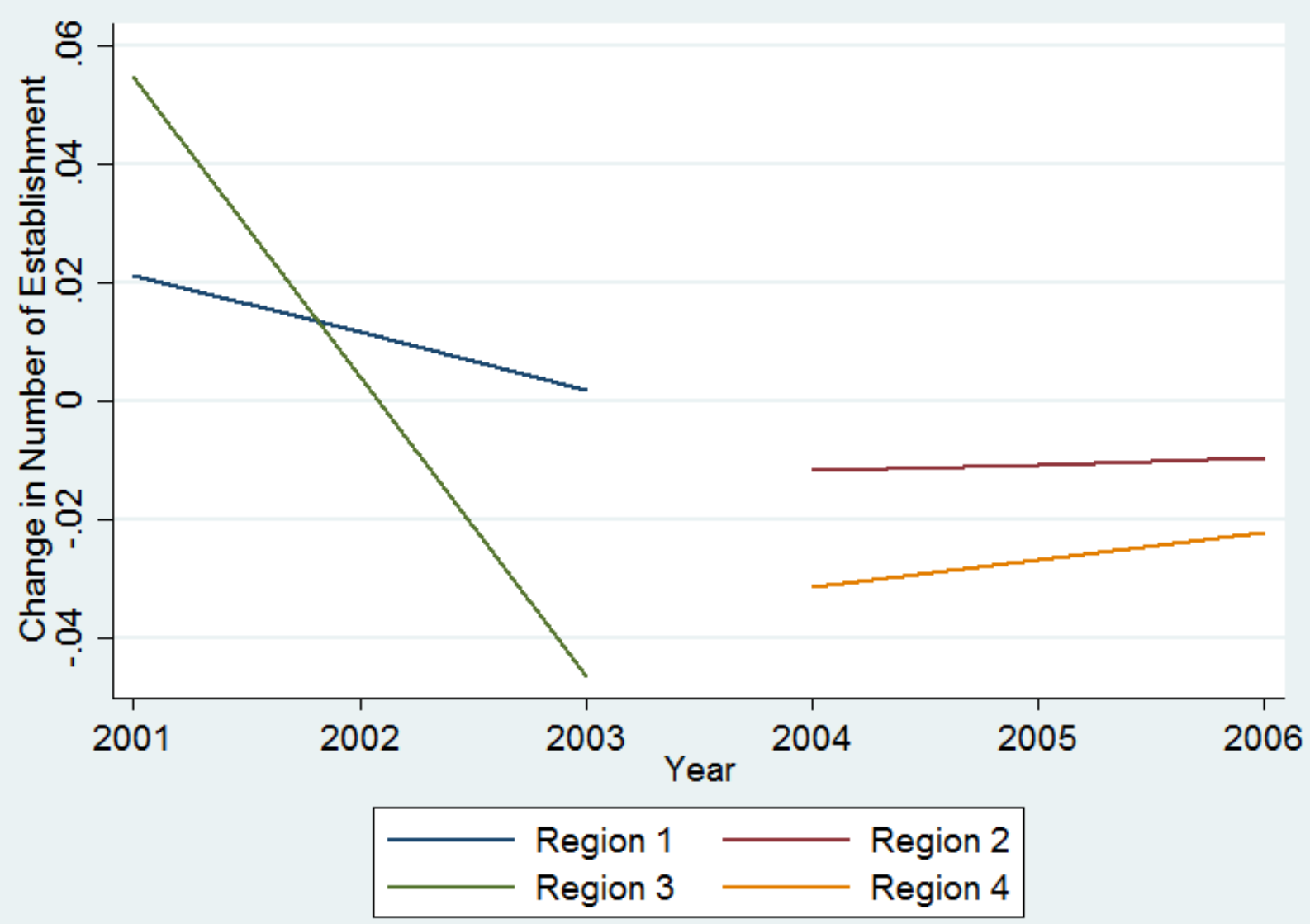

Figure 5. Plot of change in number of establishments versus time for coastal ZCTA intersections - manufacturing $\left(\Delta \mathbf{e s t}_{22}\right)$ 


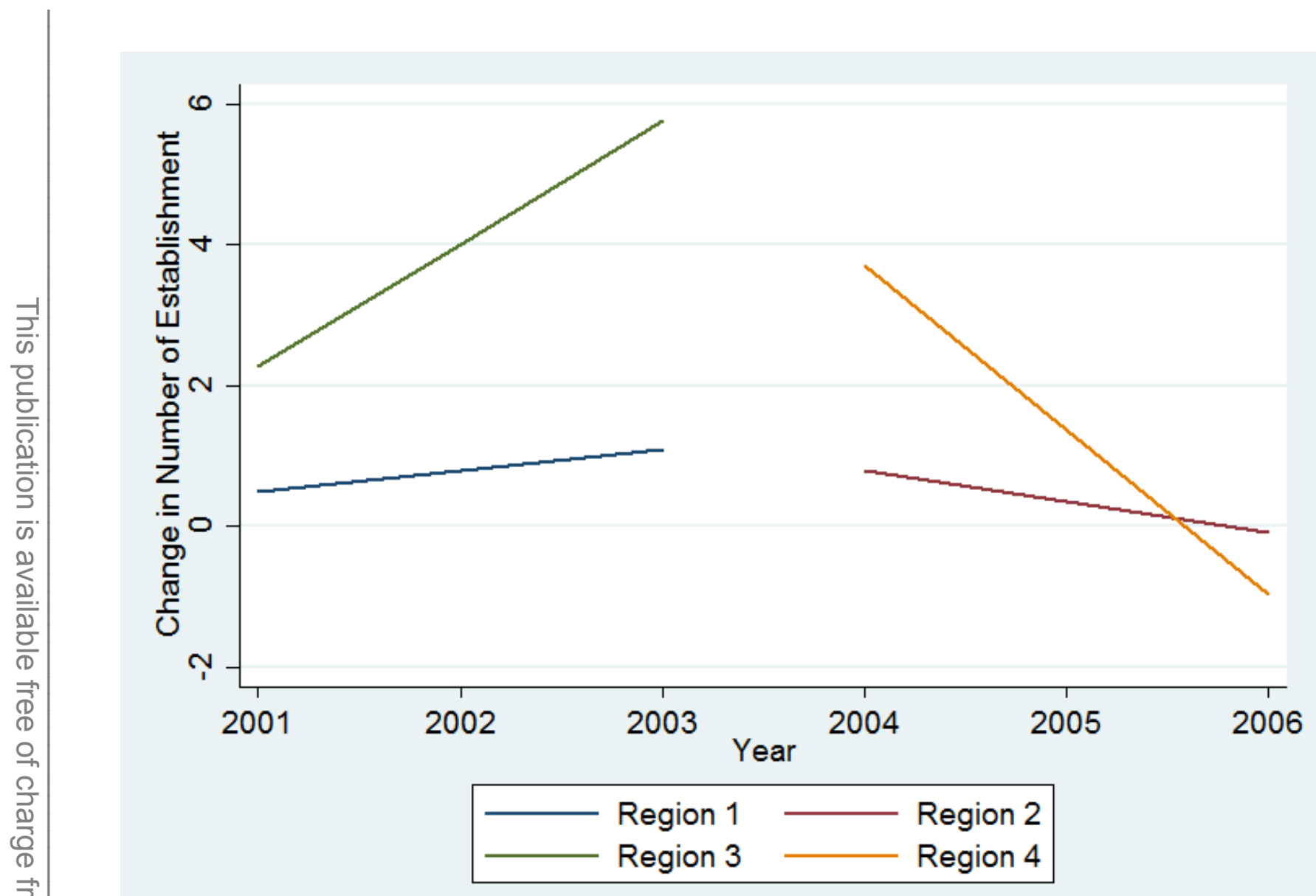

Figure 6. Plot of change in number of establishments versus time for coastal ZCTA intersections - construction $\left(\Delta \mathbf{e s t}_{23}\right)$ 


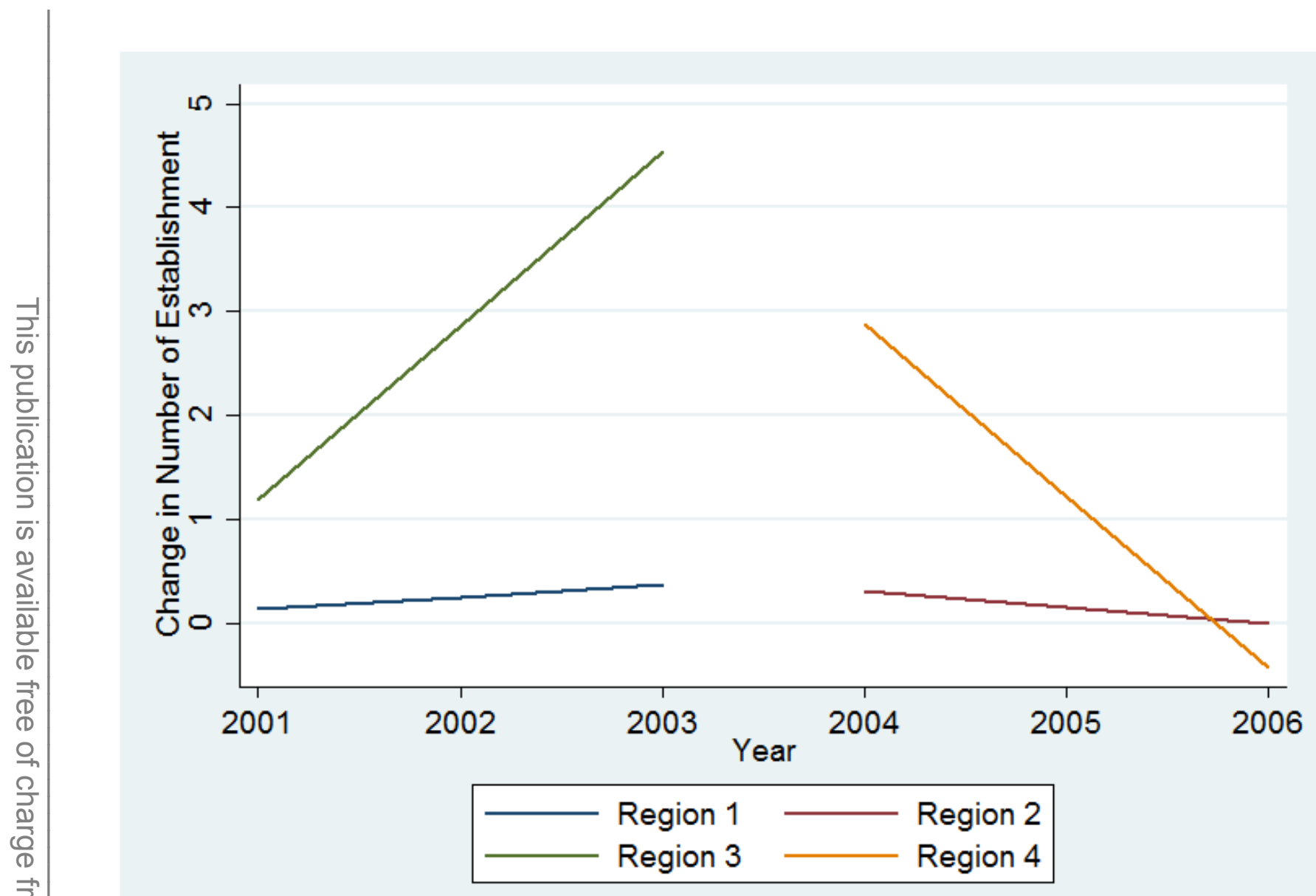

Figure 7. Plot of change in number of establishments versus time for inland ZCTA intersections - construction $\left(\Delta \mathbf{e s t}_{23}\right)$ 


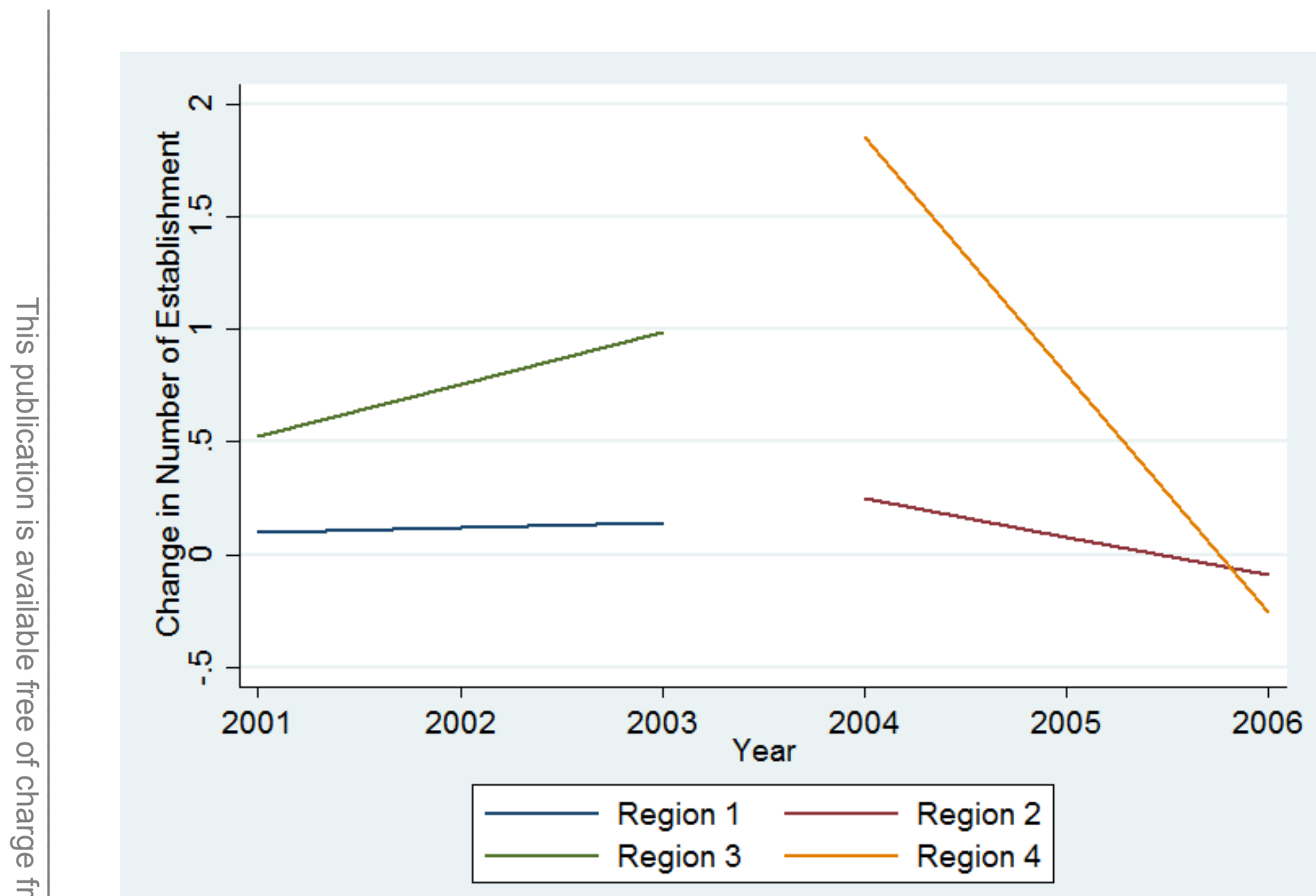

Figure 8. Plot of change in number of establishments versus time for inland ZCTA intersections - real estate $\left(\Delta \mathbf{e s t}_{53}\right)$ 


\section{Appendix B. Full regression results for individual industries}

Table 13. Regression output for inland ZCTA intersections for the utility sector $\left(\Delta \mathbf{e s t}_{22}\right)$

\begin{tabular}{|c|c|c|c|c|c|c|}
\hline \multirow[b]{3}{*}{ Variable } & \multicolumn{3}{|c|}{ No Damage-Inland (1779 Clusters) } & \multicolumn{3}{|c|}{ Damage-Inland (552 clusters) } \\
\hline & \multicolumn{3}{|c|}{$\begin{array}{c}R^{2}=0.003 \\
F-\text { test }=0.082\end{array}$} & \multicolumn{3}{|c|}{$\begin{array}{c}R^{2}=0.010 \\
F-\text { test }=0.002\end{array}$} \\
\hline & Coefficient & $\begin{array}{l}\text { Robust } \\
\text { Standard Error }\end{array}$ & p-value & Coefficient & $\begin{array}{l}\text { Robust } \\
\text { Standard Error }\end{array}$ & p-value \\
\hline$\Delta a g e_{1}$ & 0.000236 & 0.000160 & 0.140 & 0.000238 & 7.97E-05 & 0.003 \\
\hline$\Delta a g e_{2}$ & -0.000179 & 0.000164 & 0.276 & $7.96 \mathrm{E}-05$ & $9.77 \mathrm{E}-05$ & 0.416 \\
\hline$\Delta a g e_{3}$ & $-2.4 \mathrm{E}-05$ & 0.000128 & 0.852 & -0.000152 & 0.000109 & 0.162 \\
\hline$\Delta a g e_{4}$ & $3.48 \mathrm{E}-05$ & 0.000131 & 0.791 & 0.000333 & 0.000129 & 0.010 \\
\hline$\Delta$ frac $_{\text {Minority }}$ & -0.00431 & 0.0100 & 0.668 & -0.0310 & 0.107 & 0.773 \\
\hline$\Delta I n c$ & $-1.6 \mathrm{E}-07$ & $1.46 \mathrm{E}-07$ & 0.268 & $1.29 \mathrm{E}-06$ & $1.55 \mathrm{E}-06$ & 0.405 \\
\hline$\triangle O c c$ & $1.53 \mathrm{E}-05$ & 0.000171 & 0.929 & -0.000256 & 0.000155 & 0.099 \\
\hline$\Delta V a c$ & 0.000149 & 0.000227 & 0.511 & 2.97E-05 & 9.17E-05 & 0.746 \\
\hline$\Delta$ frac $_{\text {own }}$ & -0.00449 & 0.00887 & 0.613 & -0.0726 & 0.0469 & 0.123 \\
\hline year $_{2001}$ & -0.00259 & 0.00305 & 0.395 & 0.0407 & 0.0155 & 0.009 \\
\hline year $_{2002}$ & -0.00123 & 0.00255 & 0.631 & 0.0483 & 0.0160 & 0.003 \\
\hline year $_{2003}$ & -0.00409 & 0.00283 & 0.149 & 0.00657 & 0.0162 & 0.685 \\
\hline$c^{*}$ & 0.00274 & 0.00207 & 0.185 & -0.0197 & 0.00969 & 0.042 \\
\hline year $_{2005}$ & -0.00384 & 0.00324 & 0.237 & 0.00907 & 0.0125 & 0.468 \\
\hline year $_{2006}$ & -0.00262 & 0.00280 & 0.350 & 0.0112 & 0.0147 & 0.446 \\
\hline
\end{tabular}


Table 14. Regression output for coastal ZCTA intersections for the utility sector $\left(\Delta \mathbf{e s t}_{22}\right)$

\begin{tabular}{|c|c|c|c|c|c|c|}
\hline \multirow[b]{3}{*}{ Variable } & \multicolumn{3}{|c|}{ No Damage-Coastal (683 Clusters) } & \multicolumn{3}{|c|}{ Damage-Coastal (352 Clusters) } \\
\hline & \multicolumn{3}{|c|}{$\begin{array}{c}R^{2}=0.014 \\
F-\text { test }=0.002\end{array}$} & \multicolumn{3}{|c|}{$\begin{array}{c}R^{2}=0.009 \\
F-\text { test }=0.098\end{array}$} \\
\hline & Coefficient & $\begin{array}{l}\text { Robust } \\
\text { Standard Error }\end{array}$ & $p$-value & Coefficient & $\begin{array}{l}\text { Robust } \\
\text { Standard Error }\end{array}$ & $p$-value \\
\hline$\Delta a g e_{1}$ & -0.000299 & 0.000183 & 0.104 & $-6.3 \mathrm{E}-05$ & 0.000108 & 0.562 \\
\hline$\Delta a g e_{2}$ & $-6.6 \mathrm{E}-05$ & 0.000106 & 0.535 & $-1.6 \mathrm{E}-05$ & 0.000112 & 0.885 \\
\hline$\Delta a g e_{3}$ & 0.000270 & 0.000155 & 0.082 & $-2.1 \mathrm{E}-05$ & $8.02 \mathrm{E}-05$ & 0.794 \\
\hline$\Delta a g e_{4}$ & -0.000317 & 0.000147 & 0.031 & $3.02 \mathrm{E}-05$ & 0.000141 & 0.830 \\
\hline$\Delta$ frac $_{\text {Minority }}$ & -0.228 & 0.166 & 0.169 & 0.00437 & 0.468 & 0.993 \\
\hline$\Delta I n c$ & $5.02 \mathrm{E}-07$ & $6.99 \mathrm{E}-07$ & 0.473 & $-4.9 \mathrm{E}-06$ & 5.61E-06 & 0.385 \\
\hline$\Delta O c c$ & 0.000330 & 0.000116 & 0.004 & $9.48 \mathrm{E}-05$ & 0.000167 & 0.569 \\
\hline$\Delta V a c$ & -0.000244 & 0.000208 & 0.243 & $9.57 \mathrm{E}-05$ & 0.000105 & 0.364 \\
\hline$\Delta$ frac $_{\text {own }}$ & -0.306 & 0.219 & 0.162 & 0.115 & 0.675 & 0.865 \\
\hline year $_{2001}$ & 0.0376 & 0.0122 & 0.002 & 0.0789 & 0.0334 & 0.019 \\
\hline year $_{2002}$ & 0.0435 & 0.0146 & 0.003 & 0.0569 & 0.0311 & 0.068 \\
\hline year $_{2003}$ & 0.0169 & 0.0127 & 0.184 & -0.0222 & 0.0324 & 0.494 \\
\hline$c^{*}$ & -0.0213 & 0.0087 & 0.015 & -0.0357 & 0.0205 & 0.082 \\
\hline year $_{2005}$ & 0.0280 & 0.0119 & 0.019 & 0.0122 & 0.0264 & 0.643 \\
\hline year $_{2006}$ & 0.00225 & 0.0114 & 0.843 & 0.00911 & 0.0329 & 0.782 \\
\hline
\end{tabular}


Table 15. Regression output for inland ZCTA intersections for the construction sector $\left(\Delta \mathbf{e s t}_{23}\right)$

\begin{tabular}{|c|c|c|c|c|c|c|}
\hline \multirow[b]{3}{*}{ Variable } & \multicolumn{3}{|c|}{ No Damage-Inland (1779 Clusters) } & \multicolumn{3}{|c|}{ Damage-Inland (552 clusters) } \\
\hline & \multicolumn{3}{|c|}{$\begin{array}{c}R^{2}=0.240 \\
F-\text { test }<0.001\end{array}$} & \multicolumn{3}{|c|}{$\begin{array}{c}R^{2}=0.265 \\
F-\text { test }<0.001\end{array}$} \\
\hline & Coefficient & $\begin{array}{l}\text { Robust } \\
\text { Standard Error }\end{array}$ & $p$-value & Coefficient & $\begin{array}{l}\text { Robust } \\
\text { Standard Error }\end{array}$ & $p$-value \\
\hline$\Delta a g e_{1}$ & 0.000820 & 0.00446 & 0.854 & -0.00622 & 0.00249 & 0.013 \\
\hline$\Delta a g e_{2}$ & -0.00274 & 0.00551 & 0.619 & -0.00402 & 0.00283 & 0.155 \\
\hline$\Delta a g e_{3}$ & 0.0246 & 0.00446 & $<0.001$ & 0.0266 & 0.00384 & $<0.001$ \\
\hline$\Delta a g e_{4}$ & -0.00453 & 0.00687 & 0.509 & -0.00923 & 0.00422 & 0.029 \\
\hline$\Delta$ frac $_{\text {Minority }}$ & -0.667 & 0.296 & 0.024 & -0.90215 & 3.094 & 0.771 \\
\hline$\Delta \operatorname{Inc}$ & $-7.32 \mathrm{E}-06$ & 5.87E-06 & 0.213 & -0.000239 & $7.88 \mathrm{E}-05$ & 0.003 \\
\hline$\Delta O c c$ & -0.00524 & 0.00716 & 0.464 & -0.00152 & 0.00480 & 0.752 \\
\hline$\Delta V a c$ & 0.00651 & 0.00699 & 0.352 & 0.00813 & 0.00349 & 0.020 \\
\hline$\Delta$ frac $_{\text {own }}$ & -0.144 & 0.222 & 0.518 & 1.984 & 1.428 & 0.165 \\
\hline year $_{2001}$ & -0.102 & 0.0350 & 0.004 & -0.818 & 0.228 & $<0.001$ \\
\hline year $_{2002}$ & -0.184 & 0.0360 & $<0.001$ & -1.465 & 0.196 & $<0.001$ \\
\hline year $_{2003}$ & 0.131 & 0.0370 & $<0.001$ & 2.514 & 0.287 & $<0.001$ \\
\hline$c^{*}$ & 0.157 & 0.0277 & $<0.001$ & 1.381 & 0.183 & $<0.001$ \\
\hline year $_{2005}$ & -0.123 & 0.0387 & 0.002 & -1.386 & 0.248 & $<0.001$ \\
\hline year $_{2006}$ & -0.325 & 0.0531 & $<0.001$ & -3.302 & 0.300 & $<0.001$ \\
\hline
\end{tabular}


Table 16. Regression output for coastal ZCTA intersections for the construction sector $\left(\Delta \mathbf{e s t}_{23}\right)$

\begin{tabular}{|c|c|c|c|c|c|c|}
\hline \multirow[b]{3}{*}{ Variable } & \multirow{2}{*}{\multicolumn{3}{|c|}{$\begin{array}{c}\text { No Damage-Coastal (683 Clusters) } \\
R^{2}=0.175 \\
F-\text { test }<0.001\end{array}$}} & \multirow{2}{*}{\multicolumn{3}{|c|}{$\begin{array}{c}\text { Damage-Coastal (352 Clusters) } \\
R^{2}=0.223 \\
F-\text { test }<0.001\end{array}$}} \\
\hline & & & & & & \\
\hline & Coefficient & $\begin{array}{l}\text { Robust } \\
\text { Standard Error }\end{array}$ & $p$-value & Coefficient & $\begin{array}{l}\text { Robust } \\
\text { Standard Error }\end{array}$ & $p$-value \\
\hline$\Delta a g e_{1}$ & -0.0115 & 0.00587 & 0.051 & -0.00207 & 0.00261 & 0.428 \\
\hline$\Delta a g e_{2}$ & -0.00290 & 0.00524 & 0.580 & -0.00248 & 0.00313 & 0.428 \\
\hline$\Delta a g e_{3}$ & 0.0244 & 0.00514 & $<0.001$ & 0.0154 & 0.00301 & $<0.001$ \\
\hline$\Delta a g e_{4}$ & -0.0108 & 0.00632 & 0.088 & 0.000302 & 0.00365 & 0.934 \\
\hline$\Delta$ frac $_{\text {Minority }}$ & -1.696 & 1.275 & 0.184 & 23.211 & 13.016 & 0.075 \\
\hline$\Delta I n c$ & $-4.16 \mathrm{E}-05$ & $1.44 \mathrm{E}-05$ & 0.004 & -0.0003 & 0.000190 & 0.112 \\
\hline$\Delta O c c$ & $2.93 \mathrm{E}-06$ & 0.00678 & $\sim 1.000$ & -0.00269 & 0.00395 & 0.496 \\
\hline$\Delta V a c$ & 0.00471 & 0.00403 & 0.243 & 0.00733 & 0.00307 & 0.017 \\
\hline$\Delta$ frac $_{\text {own }}$ & -2.419 & 1.518 & 0.112 & 38.890 & 19.652 & 0.049 \\
\hline year $_{2001}$ & -0.168 & 0.131 & 0.199 & -0.255 & 0.389 & 0.513 \\
\hline year $_{2002}$ & -0.417 & 0.0980 & $<0.001$ & -1.718 & 0.342 & $<0.001$ \\
\hline year $_{2003}$ & 0.435 & 0.124 & $<0.001$ & 3.226 & 0.410 & $<0.001$ \\
\hline$c^{*}$ & 0.473 & 0.0866 & $<0.001$ & 2.321 & 0.303 & $<0.001$ \\
\hline year $_{2005}$ & -0.614 & 0.122 & $<0.001$ & -2.047 & 0.372 & $<0.001$ \\
\hline year $_{2006}$ & -0.877 & 0.143 & $<0.001$ & -4.642 & 0.465 & $<0.001$ \\
\hline
\end{tabular}


Table 17. Regression output for inland ZCTA intersections for the manufacturing sector $\left(\Delta \mathbf{e s t}_{31}\right)$

\begin{tabular}{|c|c|c|c|c|c|c|}
\hline \multirow[b]{3}{*}{ Variable } & \multicolumn{3}{|c|}{ No Damage-Inland (1779 Clusters) } & \multicolumn{3}{|c|}{ Damage-Inland (552 clusters) } \\
\hline & \multicolumn{3}{|c|}{$\begin{array}{c}R^{2}=0.022 \\
F-\text { test }<0.001\end{array}$} & \multicolumn{3}{|c|}{$\begin{array}{c}R^{2}=0.022 \\
F-\text { test }<0.001\end{array}$} \\
\hline & Coefficient & $\begin{array}{l}\text { Robust } \\
\text { Standard Error }\end{array}$ & $p$-value & Coefficient & $\begin{array}{l}\text { Robust } \\
\text { Standard Error }\end{array}$ & $p$-value \\
\hline$\Delta a g e_{1}$ & 0.000132 & 0.000911 & 0.885 & 0.000225 & 0.000547 & 0.681 \\
\hline$\Delta a g e_{2}$ & -0.00254 & 0.00126 & 0.043 & -0.00120 & 0.000696 & 0.084 \\
\hline$\Delta a g e_{3}$ & -0.000736 & 0.000729 & 0.313 & -0.00138 & 0.000534 & 0.010 \\
\hline$\Delta a g e_{4}$ & -0.00413 & 0.00164 & 0.012 & -0.00166 & 0.000849 & 0.051 \\
\hline$\Delta$ frac $_{\text {Minority }}$ & 0.0109 & 0.0708 & 0.878 & 0.434 & 0.793 & 0.585 \\
\hline$\Delta \operatorname{Inc}$ & $-1.74 \mathrm{E}-06$ & $1.35 \mathrm{E}-06$ & 0.196 & $-1.45 \mathrm{E}-05$ & 9.17E-06 & 0.114 \\
\hline$\Delta O c c$ & 0.00535 & 0.00172 & 0.002 & 0.00336 & 0.00104 & 0.001 \\
\hline$\Delta V a c$ & -0.00289 & 0.00149 & 0.053 & 0.000171 & 0.000428 & 0.689 \\
\hline$\Delta$ frac $_{\text {own }}$ & -0.127 & 0.0550 & 0.021 & -0.153 & 0.675 & 0.821 \\
\hline year $_{2001}$ & -0.0225 & 0.0191 & 0.239 & 0.0197 & 0.0824 & 0.811 \\
\hline year $_{2002}$ & 0.00867 & 0.0146 & 0.553 & 0.0411 & 0.0684 & 0.548 \\
\hline year $_{2003}$ & -0.00372 & 0.0170 & 0.826 & -0.0873 & 0.0686 & 0.204 \\
\hline$c^{*}$ & 0.000230 & 0.00991 & 0.982 & 0.0225 & 0.0479 & 0.639 \\
\hline year $_{2005}$ & 0.0122 & 0.0166 & 0.463 & -0.0480 & 0.0688 & 0.486 \\
\hline year $_{2006}$ & 0.00969 & 0.0131 & 0.459 & 0.0457 & 0.0728 & 0.530 \\
\hline
\end{tabular}


Table 18. Regression output for coastal ZCTA intersections for the manufacturing sector $\left(\Delta \mathbf{e s t}_{31}\right)$

\begin{tabular}{|c|c|c|c|c|c|c|}
\hline \multirow[b]{3}{*}{ Variable } & \multirow{2}{*}{\multicolumn{3}{|c|}{$\begin{array}{c}\text { No Damage-Coastal (683 Clusters) } \\
R^{2}=0.049 \\
F-\text { test }<0.001\end{array}$}} & \multirow{2}{*}{\multicolumn{3}{|c|}{$\begin{array}{c}\text { Damage-Coastal (352 Clusters) } \\
R^{2}=0.034 \\
F-\text { test }<0.001\end{array}$}} \\
\hline & & & & & & \\
\hline & Coefficient & $\begin{array}{l}\text { Robust } \\
\text { Standard Error }\end{array}$ & $p$-value & Coefficient & $\begin{array}{l}\text { Robust } \\
\text { Standard Error }\end{array}$ & $p$-value \\
\hline$\Delta a g e_{1}$ & -0.00266 & 0.00115 & 0.021 & 0.002574 & 0.00102 & 0.012 \\
\hline$\Delta a g e_{2}$ & 0.000541 & 0.000949 & 0.569 & -0.00206 & 0.00145 & 0.156 \\
\hline$\Delta a g e_{3}$ & -0.000347 & 0.000855 & 0.685 & -0.00228 & 0.000929 & 0.015 \\
\hline$\Delta a g e_{4}$ & -0.00159 & 0.00172 & 0.355 & -0.000769 & 0.00153 & 0.615 \\
\hline$\Delta f r a c_{\text {Minority }}$ & 0.231 & 0.296 & 0.435 & 3.812 & 3.596 & 0.290 \\
\hline$\Delta I n c$ & $-2.20 \mathrm{E}-06$ & 4.87E-06 & 0.651 & $9.25 \mathrm{E}-06$ & 4.77E-05 & 0.846 \\
\hline$\Delta O c c$ & 0.00354 & 0.00167 & 0.034 & 0.00314 & 0.00192 & 0.102 \\
\hline$\Delta V a c$ & -0.00282 & 0.000981 & 0.004 & -0.000128 & 0.000754 & 0.865 \\
\hline$\Delta$ frac $_{\text {own }}$ & 0.0104 & 0.367 & 0.978 & -12.185 & 5.420 & 0.025 \\
\hline year $_{2001}$ & -0.212 & 0.0522 & $<0.001$ & -0.0921 & 0.161 & 0.570 \\
\hline year $_{2002}$ & -0.0727 & 0.0528 & 0.168 & -0.0510 & 0.1544 & 0.741 \\
\hline year $_{2003}$ & -0.0321 & 0.0408 & 0.433 & -0.227 & 0.153 & 0.140 \\
\hline$c^{*}$ & 0.0253 & 0.0287 & 0.378 & -0.0889 & 0.115 & 0.441 \\
\hline year $_{2005}$ & -0.0582 & 0.0380 & 0.126 & -0.0330 & 0.142 & 0.817 \\
\hline year $_{2006}$ & -0.0210 & 0.0487 & 0.667 & 0.256 & 0.168 & 0.129 \\
\hline
\end{tabular}


Table 19. Regression output for inland ZCTA intersections for the wholesale retail sector $\left(\Delta \mathbf{e s t}_{42}\right)$

\begin{tabular}{|c|c|c|c|c|c|c|}
\hline \multirow[b]{3}{*}{ Variable } & \multicolumn{3}{|c|}{ No Damage-Inland (1779 Clusters) } & \multicolumn{3}{|c|}{ Damage-Inland (552 clusters) } \\
\hline & \multicolumn{3}{|c|}{$\begin{array}{c}R^{2}=0.026 \\
F-\text { test }<0.001\end{array}$} & \multicolumn{3}{|c|}{$\begin{array}{c}R^{2}=0.038 \\
F-\text { test }<0.001\end{array}$} \\
\hline & Coefficient & $\begin{array}{l}\text { Robust } \\
\text { Standard Error }\end{array}$ & $p$-value & Coefficient & $\begin{array}{l}\text { Robust } \\
\text { Standard Error }\end{array}$ & $p$-value \\
\hline$\Delta a g e_{1}$ & -0.00167 & 0.00336 & 0.619 & 0.00191 & 0.00150 & 0.204 \\
\hline$\Delta a g e_{2}$ & -0.00233 & 0.00436 & 0.592 & -0.00406 & 0.00284 & 0.154 \\
\hline$\Delta a g e_{3}$ & 0.00668 & 0.00363 & 0.066 & $-6.65 E-05$ & 0.00174 & 0.970 \\
\hline$\Delta a g e_{4}$ & -0.00376 & 0.00451 & 0.404 & -0.00695 & 0.00431 & 0.108 \\
\hline$\Delta$ frac $_{\text {Minority }}$ & -0.732 & 0.270 & 0.007 & -4.509 & 3.600 & 0.211 \\
\hline$\Delta \operatorname{Inc}$ & $-1.14 \mathrm{E}-05$ & $4.73 \mathrm{E}-06$ & 0.016 & $-5.46 \mathrm{E}-05$ & $2.73 \mathrm{E}-05$ & 0.046 \\
\hline$\Delta O c c$ & 0.00461 & 0.00598 & 0.440 & 0.00755 & 0.00483 & 0.118 \\
\hline$\Delta V a c$ & -0.0130 & 0.00614 & 0.035 & 0.000641 & 0.00146 & 0.661 \\
\hline$\Delta$ frac $_{\text {own }}$ & -0.516 & 0.169 & 0.002 & -3.737 & 3.701 & 0.313 \\
\hline year $_{2001}$ & 0.101 & 0.0464 & 0.029 & 0.122 & 0.138 & 0.376 \\
\hline year $_{2002}$ & 0.121 & 0.0395 & 0.002 & 0.172 & 0.134 & 0.201 \\
\hline year $_{2003}$ & -0.0202 & 0.0195 & 0.300 & -0.170 & 0.128 & 0.183 \\
\hline$c^{*}$ & -0.0258 & 0.0200 & 0.199 & 0.165 & 0.092 & 0.075 \\
\hline year $_{2005}$ & 0.0244 & 0.0297 & 0.411 & -0.328 & 0.149 & 0.028 \\
\hline year $_{2006}$ & 0.0608 & 0.0263 & 0.021 & 0.0354 & 0.180 & 0.844 \\
\hline
\end{tabular}


Table 20. Regression output for coastal ZCTA intersections for the wholesale retail sector $\left(\Delta \mathbf{e s t}_{42}\right)$

\begin{tabular}{|c|c|c|c|c|c|c|}
\hline \multirow[b]{3}{*}{ Variable } & \multirow{2}{*}{\multicolumn{3}{|c|}{$\begin{array}{c}\text { No Damage-Coastal (683 Clusters) } \\
R^{2}=0.025 \\
F-\text { test }<0.001\end{array}$}} & \multirow{2}{*}{\multicolumn{3}{|c|}{$\begin{array}{c}\text { Damage-Coastal (352 Clusters) } \\
R^{2}=0.025 \\
F-\text { test }<0.001\end{array}$}} \\
\hline & & & & & & \\
\hline & Coefficient & $\begin{array}{l}\text { Robust } \\
\text { Standard Error }\end{array}$ & $p$-value & Coefficient & $\begin{array}{l}\text { Robust } \\
\text { Standard Error }\end{array}$ & $p$-value \\
\hline$\Delta a g e_{1}$ & -0.00103 & 0.00239 & 0.666 & 0.00324 & 0.00159 & 0.041 \\
\hline$\Delta a g e_{2}$ & $9.24 \mathrm{E}-05$ & 0.00141 & 0.948 & -0.000981 & 0.00277 & 0.724 \\
\hline$\Delta a g e_{3}$ & 0.00432 & 0.00207 & 0.037 & -0.000421 & 0.00164 & 0.798 \\
\hline$\Delta a g e_{4}$ & -0.000384 & 0.00352 & 0.913 & -0.000834 & 0.00282 & 0.768 \\
\hline$\Delta f r a c_{\text {Minority }}$ & 0.102 & 0.968 & 0.916 & -0.0750 & 8.653 & 0.993 \\
\hline$\Delta I n c$ & $-4.35 E-05$ & $1.87 \mathrm{E}-05$ & 0.020 & -0.000123 & 0.000148 & 0.409 \\
\hline$\Delta O c c$ & 0.000207 & 0.00318 & 0.948 & 0.00155 & 0.00333 & 0.642 \\
\hline$\Delta V a c$ & -0.00170 & 0.00286 & 0.553 & 0.00145 & 0.00152 & 0.342 \\
\hline$\Delta$ frac $_{\text {own }}$ & 0.448 & 1.103 & 0.685 & -15.802 & 15.820 & 0.319 \\
\hline year $_{2001}$ & 0.257 & 0.151 & 0.089 & 0.638 & 0.282 & 0.024 \\
\hline year $_{2002}$ & 0.0682 & 0.0807 & 0.399 & 0.643 & 0.269 & 0.017 \\
\hline year $_{2003}$ & -0.258 & 0.0789 & 0.001 & -0.456 & 0.319 & 0.153 \\
\hline$c^{*}$ & 0.000116 & 0.0554 & 0.998 & -0.214 & 0.164 & 0.194 \\
\hline year $_{2005}$ & -0.184 & 0.0779 & 0.018 & -0.0182 & 0.231 & 0.937 \\
\hline year $_{2006}$ & 0.117 & 0.119 & 0.324 & 0.0883 & 0.356 & 0.804 \\
\hline
\end{tabular}


Table 21. Regression output for inland ZCTA intersections for the retail sector $\left(\Delta \mathbf{e s t}_{44}\right)$

\begin{tabular}{|c|c|c|c|c|c|c|}
\hline \multirow[b]{3}{*}{ Variable } & \multicolumn{3}{|c|}{ No Damage-Inland (1779 Clusters) } & \multicolumn{3}{|c|}{ Damage-Inland (552 clusters) } \\
\hline & \multicolumn{3}{|c|}{$\begin{array}{c}R^{2}=0.086 \\
F-\text { test }<0.001\end{array}$} & \multicolumn{3}{|c|}{$\begin{array}{c}R^{2}=0.137 \\
F-\text { test }<0.001\end{array}$} \\
\hline & Coefficient & $\begin{array}{l}\text { Robust } \\
\text { Standard Error }\end{array}$ & $p$-value & Coefficient & $\begin{array}{l}\text { Robust } \\
\text { Standard Error }\end{array}$ & $p$-value \\
\hline$\Delta a g e_{1}$ & -0.00970 & 0.00575 & 0.092 & -0.00889 & 0.00440 & 0.044 \\
\hline$\Delta a g e_{2}$ & 0.00677 & 0.00516 & 0.189 & -0.000661 & 0.00392 & 0.866 \\
\hline$\Delta a g e_{3}$ & 0.00621 & 0.00357 & 0.082 & 0.00212 & 0.00352 & 0.548 \\
\hline$\Delta a g e_{4}$ & -0.000629 & 0.00476 & 0.895 & -0.00980 & 0.00481 & 0.042 \\
\hline$\Delta$ frac $_{\text {Minority }}$ & -1.375 & 0.847 & 0.105 & 4.776 & 2.756 & 0.084 \\
\hline$\Delta I n c$ & $-2.15 \mathrm{E}-05$ & $1.05 \mathrm{E}-05$ & 0.041 & -0.000135 & 5.37E-05 & 0.012 \\
\hline$\Delta O c c$ & 0.00463 & 0.00659 & 0.483 & 0.0156 & 0.00522 & 0.003 \\
\hline$\Delta V a c$ & -0.00591 & 0.00603 & 0.327 & 0.00743 & 0.00473 & 0.116 \\
\hline$\Delta$ frac $_{\text {own }}$ & -1.031 & 0.671 & 0.124 & -1.122 & 1.348 & 0.405 \\
\hline year $_{2001}$ & 0.0523 & 0.0302 & 0.083 & 0.183 & 0.224 & 0.413 \\
\hline year $_{2002}$ & -0.131 & 0.0462 & 0.005 & -0.526 & 0.187 & 0.005 \\
\hline year $_{2003}$ & 0.0187 & 0.0298 & 0.531 & 0.202 & 0.218 & 0.354 \\
\hline$c^{*}$ & 0.0291 & 0.0265 & 0.272 & 0.012082 & 0.144 & 0.933 \\
\hline year $_{2005}$ & -0.0599 & 0.0351 & 0.088 & 0.074966 & 0.181 & 0.679 \\
\hline year $_{2006}$ & -0.0182 & 0.0371 & 0.624 & 0.10305 & 0.195 & 0.598 \\
\hline
\end{tabular}


Table 22. Regression output for coastal ZCTA intersections for the retail sector ( $\left.\Delta \mathbf{e s t}_{44}\right)$

\begin{tabular}{|c|c|c|c|c|c|c|}
\hline \multirow[b]{3}{*}{ Variable } & \multicolumn{3}{|c|}{ No Damage-Coastal (683 Clusters) } & \multicolumn{3}{|c|}{ Damage-Coastal (352 Clusters) } \\
\hline & \multicolumn{3}{|c|}{$\begin{array}{c}R^{2}=0.148 \\
F-\text { test }<0.001\end{array}$} & \multicolumn{3}{|c|}{$\begin{array}{c}R^{2}=0.139 \\
F-t e s t<0.001\end{array}$} \\
\hline & Coefficient & \begin{tabular}{|l|} 
Robust \\
Standard Error
\end{tabular} & p-value & Coefficient & $\begin{array}{l}\text { Robust } \\
\text { Standard Error }\end{array}$ & $\mathrm{p}$-value \\
\hline$\Delta a g e_{1}$ & -0.00990 & 0.00575 & 0.086 & -0.00262 & 0.00297 & 0.378 \\
\hline$\Delta a g e_{2}$ & -0.000454 & 0.00258 & 0.861 & -0.00198 & 0.00316 & 0.531 \\
\hline$\Delta a g e_{3}$ & 0.00414 & 0.00328 & 0.208 & 0.000916 & 0.00305 & 0.764 \\
\hline$\Delta a g e_{4}$ & -0.00867 & 0.00742 & 0.243 & 0.00125 & 0.00340 & 0.713 \\
\hline$\Delta$ frac $_{\text {Minority }}$ & -0.230 & 0.629 & 0.715 & 8.123 & 11.558 & 0.483 \\
\hline$\Delta \operatorname{Inc}$ & $-4.6 \mathrm{E}-05$ & $2.27 \mathrm{E}-05$ & 0.043 & -0.000251 & 0.000142 & 0.078 \\
\hline$\Delta O c c$ & 0.0152 & 0.00574 & 0.008 & 0.0101 & 0.00411 & 0.014 \\
\hline$\Delta V a c$ & -0.00144 & 0.00418 & 0.731 & 0.00209 & 0.00405 & 0.606 \\
\hline$\Delta$ frac $_{\text {own }}$ & -0.175 & 0.532 & 0.743 & -13.457 & 15.163 & 0.375 \\
\hline year $_{2001}$ & 0.177 & 0.136 & 0.193 & 1.129 & 0.367 & 0.002 \\
\hline year $_{2002}$ & -0.155 & 0.124 & 0.214 & -0.610 & 0.358 & 0.089 \\
\hline year $_{2003}$ & 0.0581 & 0.108 & 0.592 & 0.395 & 0.360 & 0.273 \\
\hline$c^{*}$ & 0.0101 & 0.0831 & 0.903 & 0.133 & 0.266 & 0.618 \\
\hline year $_{2005}$ & -0.106 & 0.129 & 0.411 & -0.829 & 0.342 & 0.016 \\
\hline year $_{2006}$ & -0.164 & 0.140 & 0.239 & -1.378 & 0.390 & $<0.001$ \\
\hline
\end{tabular}


Table 23. Regression output for inland ZCTA intersections for the real estate sector $\left(\Delta \mathbf{e s t}_{53}\right)$

\begin{tabular}{|c|c|c|c|c|c|c|}
\hline \multirow[b]{3}{*}{ Variable } & \multicolumn{3}{|c|}{ No Damage-Inland (1779 Clusters) } & \multicolumn{3}{|c|}{ Damage-Inland (552 clusters) } \\
\hline & \multicolumn{3}{|c|}{$\begin{array}{c}R^{2}=0.164 \\
F-\text { test }<0.001\end{array}$} & \multicolumn{3}{|c|}{$\begin{array}{c}R^{2}=0.163 \\
F-\text { test }<0.001\end{array}$} \\
\hline & Coefficient & $\begin{array}{l}\text { Robust } \\
\text { Standard Error }\end{array}$ & $p$-value & Coefficient & $\begin{array}{l}\text { Robust } \\
\text { Standard Error }\end{array}$ & $p$-value \\
\hline$\Delta a g e_{1}$ & -0.00649 & 0.00420 & 0.123 & -0.00246 & 0.00159 & 0.123 \\
\hline$\Delta a g e_{2}$ & -0.00182 & 0.00417 & 0.662 & -0.000449 & 0.00133 & 0.735 \\
\hline$\Delta a g e_{3}$ & 0.00990 & 0.00339 & 0.004 & 0.00482 & 0.00134 & $<0.001$ \\
\hline$\Delta a g e_{4}$ & -0.00383 & 0.00455 & 0.400 & -0.00297 & 0.00180 & 0.101 \\
\hline$\Delta$ frac $_{\text {Minority }}$ & -0.102 & 0.223 & 0.648 & 0.681 & 1.651 & 0.680 \\
\hline$\Delta \operatorname{Inc}$ & $-5.95 E-06$ & $4.70 \mathrm{E}-06$ & 0.206 & -0.000137 & $5.55 \mathrm{E}-05$ & 0.014 \\
\hline$\Delta O c c$ & 0.00356 & 0.00630 & 0.572 & 0.00108 & 0.00205 & 0.600 \\
\hline$\Delta V a c$ & 0.00891 & 0.00547 & 0.104 & 0.0122 & 0.00200 & $<0.001$ \\
\hline$\Delta$ frac $_{\text {own }}$ & -0.00830 & 0.183 & 0.964 & 0.955 & 0.879 & 0.278 \\
\hline year $_{2001}$ & -0.142 & 0.0279 & $<0.001$ & -1.141 & 0.172 & $<0.001$ \\
\hline year $_{2002}$ & -0.156 & 0.0276 & $<0.001$ & -1.273 & 0.160 & $<0.001$ \\
\hline year $_{2003}$ & -0.100 & 0.0253 & $<0.001$ & -0.677 & 0.143 & $<0.001$ \\
\hline$c^{*}$ & 0.166 & 0.0259 & $<0.001$ & 1.186 & 0.127 & $<0.001$ \\
\hline year $_{2005}$ & -0.178 & 0.0331 & $<0.001$ & -0.866 & 0.160 & $<0.001$ \\
\hline year $_{2006}$ & -0.341 & 0.0496 & $<0.001$ & -2.106 & 0.237 & $<0.001$ \\
\hline
\end{tabular}


Table 24. Regression output for coastal ZCTA intersections for the real estate sector $\left(\Delta \mathbf{e s t}_{53}\right)$

\begin{tabular}{|c|c|c|c|c|c|c|}
\hline \multirow[b]{3}{*}{ Variable } & \multicolumn{3}{|c|}{ No Damage-Coastal (683 Clusters) } & \multicolumn{3}{|c|}{ Damage-Coastal (352 Clusters) } \\
\hline & \multicolumn{3}{|c|}{$\begin{array}{c}R^{2}=0.131 \\
F-\text { test }<0.001\end{array}$} & \multicolumn{3}{|c|}{$\begin{array}{c}R^{2}=0.181 \\
F-\text { test }<0.001\end{array}$} \\
\hline & Coefficient & $\begin{array}{l}\text { Robust } \\
\text { Standard Error }\end{array}$ & p-value & Coefficient & $\begin{array}{l}\text { Robust } \\
\text { Standard Error }\end{array}$ & p-value \\
\hline$\Delta a g e_{1}$ & -0.00204 & 0.00347 & 0.557 & 0.00199 & 0.00149 & 0.185 \\
\hline$\Delta a g e_{2}$ & -0.00270 & 0.00209 & 0.197 & -0.00216 & 0.00202 & 0.286 \\
\hline$\Delta a g e_{3}$ & 0.00924 & 0.00307 & 0.003 & 0.00422 & 0.00139 & 0.003 \\
\hline$\Delta a g e_{4}$ & -0.00778 & 0.00432 & 0.072 & 0.000760 & 0.00205 & 0.711 \\
\hline$\Delta$ frac $_{\text {Minority }}$ & -0.350 & 0.529 & 0.508 & -2.536 & 6.183 & 0.682 \\
\hline$\Delta \operatorname{Inc}$ & $-2.73 \mathrm{E}-05$ & $1.08 \mathrm{E}-05$ & 0.012 & $-2.98 \mathrm{E}-05$ & 9.65E-05 & 0.758 \\
\hline$\Delta O c c$ & 0.00261 & 0.00370 & 0.480 & -0.00114 & 0.00241 & 0.635 \\
\hline$\Delta V a c$ & 0.00862 & 0.00378 & 0.023 & 0.00648 & 0.00149 & $<0.001$ \\
\hline$\Delta$ frac $_{\text {own }}$ & 0.639 & 0.542 & 0.239 & 16.171 & 9.123 & 0.077 \\
\hline year $_{2001}$ & -0.327 & 0.103 & 0.002 & -1.457 & 0.290 & $<0.001$ \\
\hline year $_{2002}$ & -0.440 & 0.0919 & $<0.001$ & -2.221 & 0.259 & $<0.001$ \\
\hline year $_{2003}$ & -0.157 & 0.0991 & 0.114 & -1.535 & 0.254 & $<0.001$ \\
\hline$c^{*}$ & 0.598 & 0.0879 & $<0.001$ & 2.760 & 0.244 & $<0.001$ \\
\hline year $_{2005}$ & -0.640 & 0.112 & $<0.001$ & -3.041 & 0.343 & $<0.001$ \\
\hline year $_{2006}$ & -1.506 & 0.178 & $<0.001$ & -5.486 & 0.426 & $<0.001$ \\
\hline
\end{tabular}

